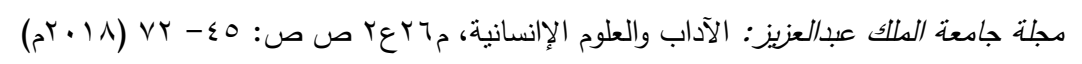

DOI:10.4197 / Art.26-2.3

الأسُس الفَلسفيّة للنّّوية عَرض ونقُّ وأثنرُ ذلك عَلى النَّسيّة الإسلاميّة

د.خالد بن عبد العزيز السيف

أستاذ مشارك في كلية الثريعة والدراسات الإسلامية

قسم العقبية والمذاهب المعاصرة

جامعة القصبم

kasaif@gmail.com

مستخلص تعثبر الحركات النسوية من أكثر الحركات إنارة للجدل، وهذه الحركات لم تكن تتم لولا توفير الدعم

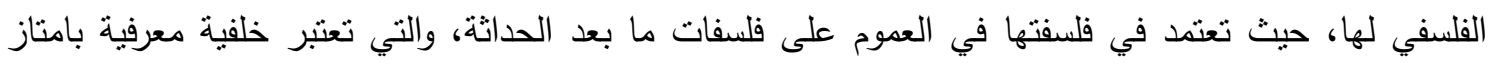

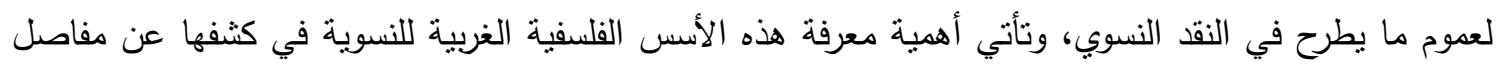
الفكر النسوي العربي حيث ينبين للناقد أن الفكر النسوي العربي ما هو إلا صدى للفئي للفكر النسوي الغربي.

والقول إن الحركات النسوية من أكثر الحركات إثارة

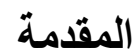

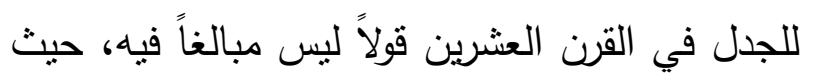
تمنت المرأة جزءً من تمظهر المشكلة في مجال حقوق الإنسان؛ حيث بدأت المشكلة في العالم الغربي بمراجعة كافة الأسس والتشريعات سواء ما لإنسات كانت مصاغة كقوانين مكتوبة، أو كقوانين

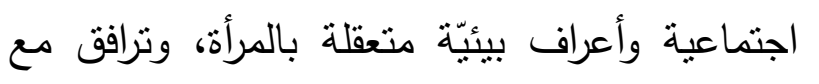

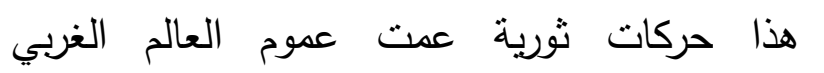

إن الحمد لله ونحمد ونستعينه ونستغفره ونعوذ باله

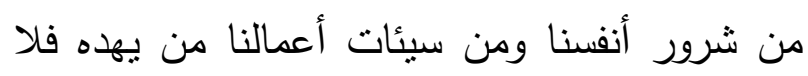

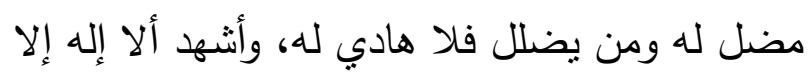
إله وحده لا شريك له وأثشه أن محمداً عبده ورسوله

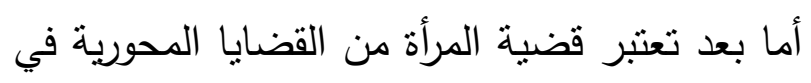
العالم العربي وهذا جزء من انعكاس الحركة الحقوقية

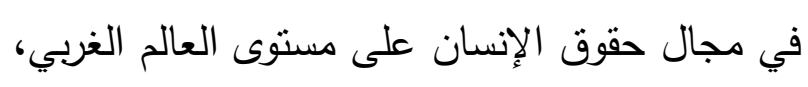


بامتاز لعموم ما يطرح في النقد النسوي، وتأني أهمية معرفة هذه الأسس الفلسفية الغربية في كثفها عن بطن مفاصل الفكر النسوي العربي حيث يتبين للناقد أن

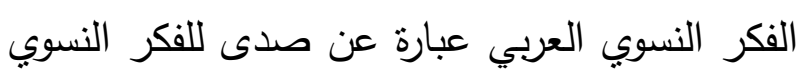
الغربي ـ لذلك فإنه مع المقارنة المنهجية للاراسات النسوية العربية في عموم ما يطرح فيها من القضايا

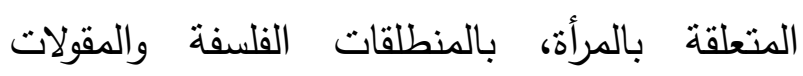

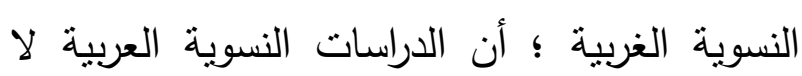

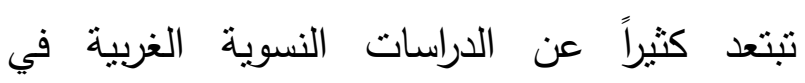
المضمون وفي الثكل أحياناً، فعموم المنطلقات والأسس واحدة وإن كانت تختلف أحياناً في درجة الإعمال والاثتتغال، أما النتائج فقد نكون في العموم الأغلب منطابقة إلى حد ما وستأتي الإثشارة إلى هذا قريباً .

وهناك بعض الدراسات السابقة في هذا الموضوع كرسالة "الاتجاه النسوي في الفكر المعاصر دراسة نقدية" لسامية العنزي ، وهي رسالة ماجستير في قسم

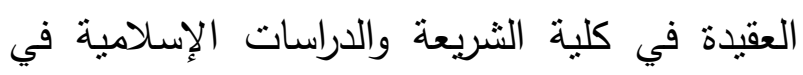
جامعة القصيم وهي مطبوعة ، والرسالة متميزة

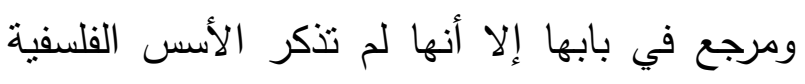

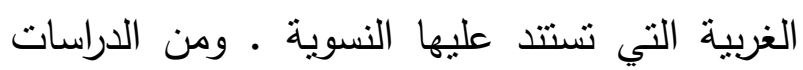
السابقة أيضاً "مفهوم النسوية دراسة نقدية في ضوه الإسلام" لأمل الخريف، وهي بحث تكميلي لمرحلة الماجستير في قسم الثقافة الإسلامية في كلية

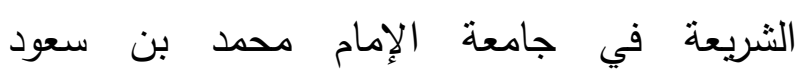
الإسلامية، وهذا البحث متميز في مسائله إلا أن الن
والولايات المتحدة الأمريكية على وجه الخصوص تطالب بمزيد من منح المرأة كافة حقوقها وبالمطالبة برفع القيود الصارمة عليها، وتزامن مع هذا أيضاً حركات نقدية ثقافية بدأت بدراسة وضع المرأة في

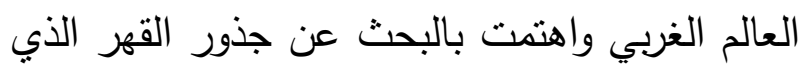

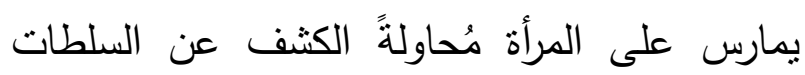

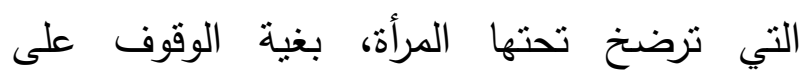
المفاصل الجوهرية التي أوصلت المرأة إلى هذا لترضئ

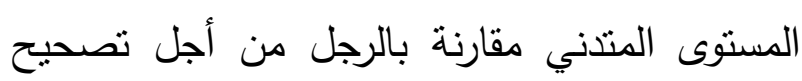
الوضع النسوي والنهوض بالأنثى إلى مصاف الذكر .

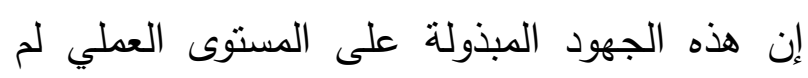
يكن لها أن تتم لولا توفير الدعم النظري والمسوغ لهن الفلسفي لها، حيث يمنل المسوغ الفلسفي والفكري مشروعية لهذه الجهود ويعطيها المساحة للامتداد، ويكسّر قنوات المقاومة، ويقنع الجماهير المترددة بصوابيّة الحركات التحررية .

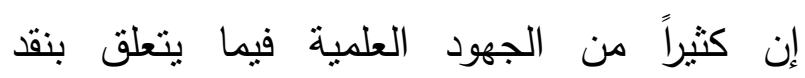
الاتجاهات النسوية تتصرف إلى المهية النضالية والمدافعة في بعض القضايا التي قد تشتد سخونتها في هذا الوقت بالذات، وهذا لا يقل من القيمة العلمية

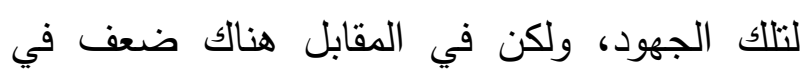
الدراسات التأسيسية النظرية التي تغطي في الجانب الفلسفي والفكري لمنطلقات الحركات النسوية، ولذلك يأتي الحديث عن الأسس الفلسفية كمقدمة نظرية مختصرة لأهم المنطلقات الفلسفية التي اعتمدت التين عليها النسوية الغربية، والتي تعتبر خلفية معرفية 
المبحث الأول: مفهوم النسوية

المبحث الثاني: إثكالية المصطلح في الدراسات النسوية في الفكر العربي المعاصر

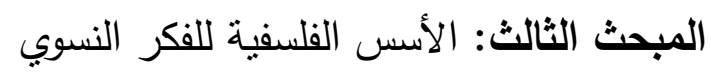
المطلب الأول: الماركسية في خدمة النسوية المطلب الثاني: المعرفة والسلطة مدخل جديد للنسوية المطلب الثالث: التفكيك النسوي المبحث الرابع: امتدادات الأسس الفلسفية للنسوية

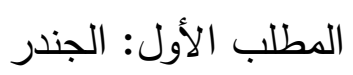
المطلب الثاني: البطريركية/الأبوية المبحث الخامس: انعكاس الأسس الفلسفية الغربية على النسوية الإسلامية المبحث السادس: الموقف النقدي من الأسس الإسلة الفلسفية للنسوية

\section{خاتمة}

\section{المبحث الأول: مفهوم النسوية}

ظهر مصطلح "النسوية" في تسعينيات القرن التاسع عشر (') ويفرق بعض الباحثين بين النسوية كفلسفة فئية

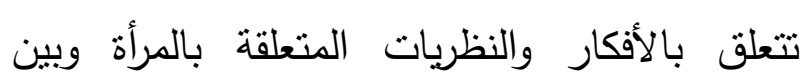

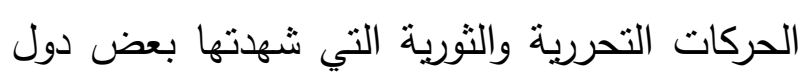
العالم للمطالبة بحقوق النساء، وهذا التقريق مهر في دراسة الجانب النظري للنسوية، من حيث إن النسوية في جانبها النظري والفلسفي هي حزمة من النظريات

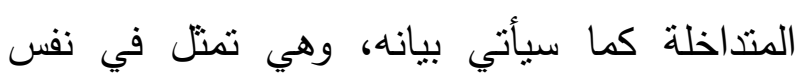

\footnotetext{
(1) انظر مفاهيم اصطلاحية جديدة معجم مصطلحات الثقافة والمجتمع،

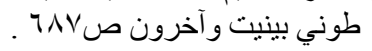

اهتمامه على المصطلح وآثاره ولم يعتن بالأسس الفلسفية الغربية التي تتطلق منها النسوية . وإن الهدف والجديد في هذا البحث هو دراسة الأسس الفلسفية للنسوية ومعرفة مدى ثأثز النسوية العربية في دراساتها وفي تتاولها لقضايا المرأة بالنسوية النوية العندية

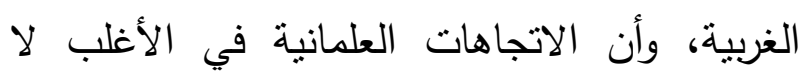
تخرج عن مخرجات الفلسفية الغربية في تتاولها لهذه القضايا وفي غيرها، وهذا جزء من مشكلة العولمة

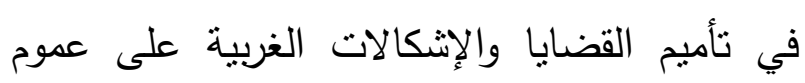
الثعوب، وهنا يتأكد أن العلمانية العربية علمانية غير مبدعة بل هي مجرد ناقل بسنورد المشاكل كما

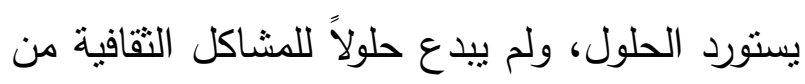

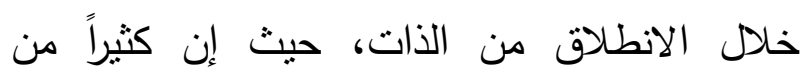

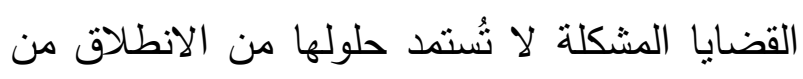

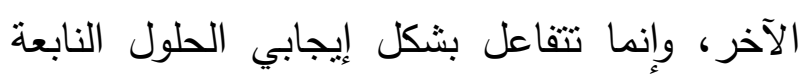
من الذات ومن الذات فقط، وهذه الأوراق هي إثشارات مختصرة عن الأسس الفلسفية للنسوية مراعياً فيها

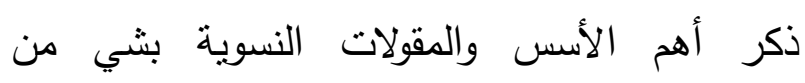

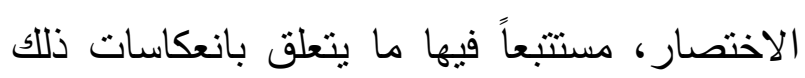

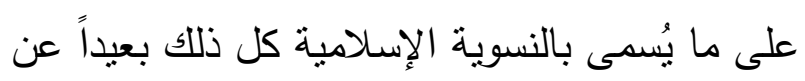

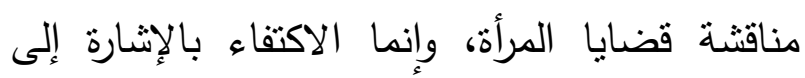

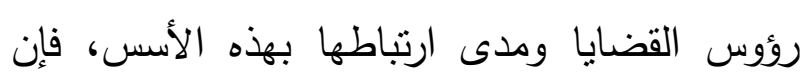
دراسة هذه القضايا لها مجالها الخاص . وقد سرت في هذا البحث على الخطة التالية: المقدمة 
في الميادين الثقافية على قدم المساواة مع الرجل،

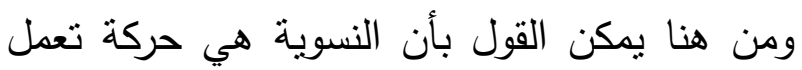
على تغيير هذه الأوضاع لتحقيق تلاك المساواة"(") ولذلك فالنسوية في جانبها الفلسفي هي جزء من النقد الثقافي حيث بدأ ظهورها كحركة نقدية كما يقول هن هن حفناوي بعلي(؛):"منذ ما يقارب من ثلاثين عاماً(ه) وهو فرع من فروع النقد الثقافي الذي تعتمد عليه

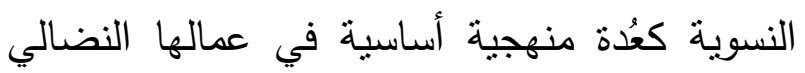
في الكثف عن تداعيات الثقافة الذكورية التي لا لانيه

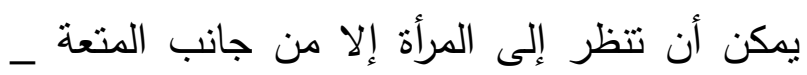

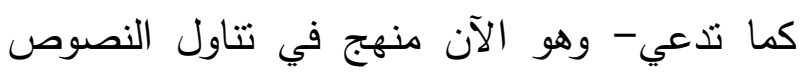
والتحليل الثقافي بصفة عامة، وينشغل النقد النسوي

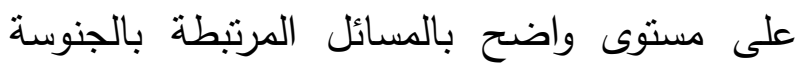

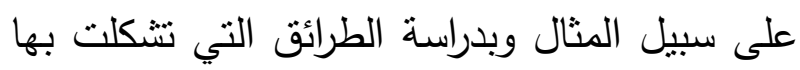
صورة المرأة .. وبأمور أخرى مثل صورة المرأة في لتصني النصوص الدرامية والاستغلال الجنسي لجسد المرأة،

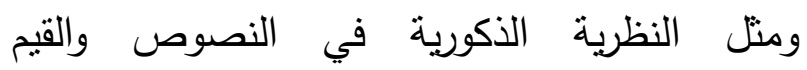
والمعتقدات الموجهة بالدرجة الأولى مباشرة للمرأة

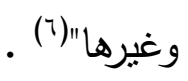

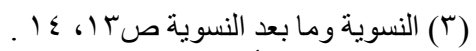

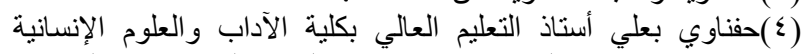

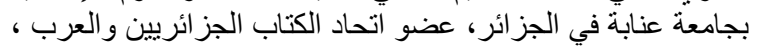

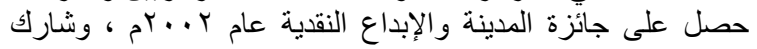

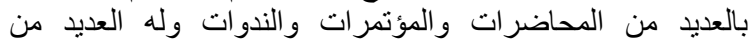
المؤلفات والبحوث . انظر مدخل إلى النقد النسوي وما بعد النسوي النّات rov

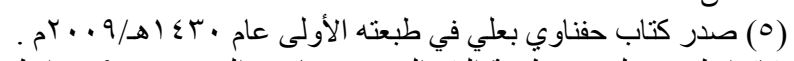

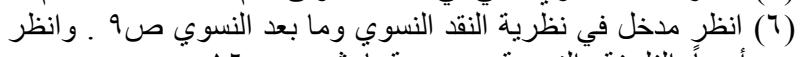

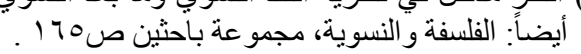

الوقت دعامة منطقية للحركات التحررية، بل إنها تعتبر هي الوقود الفعلي الذي أعطى المنظمات

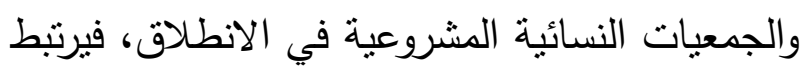
بمصطلح النسوية حسب موسوعة اكسفورد:"فروق دقيقة في المعنى - بالمعنى الضيق - بحيث يثير إلى محاولة الحصول على حقوق سياسية وقانونية مساوية للنساء، في حين يثير معناه الواسع إلى كل نظرية تعتبر العلاقة بين الجنسين علاقة إجحاف

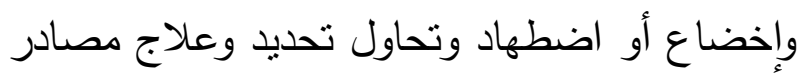
ذلك"(') وتعطي سارة جامبل (؟)

وهي المهتمة بالدراسات النسائية مفهوماً أكثز شمولية لمصطلح النسوية حيث ترى أن:" التعريف دالني العام للنسوية يشير إلى أنها تعني الاعتقاد بأن المرأة لا نعامل على قدم المساواة - لأي سبب سوى كونها امرأة - في المجتمع الذي بنظم شؤونه ويحدد أولياته حسب روئة الرجل واهتماماته، وفي ظل هذا النظام الأبوي تصبح المرأة هي كل مالا يميز الرجل أو كل

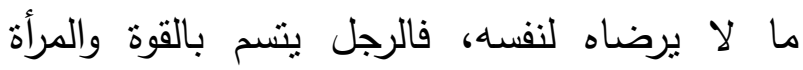

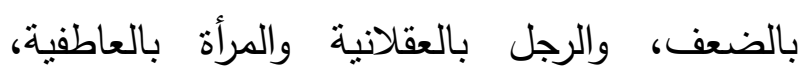

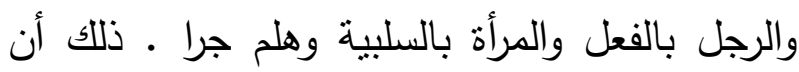
المنظور يقرن المرأة في كل مكان بالسلبية، وينكر باه بالبه

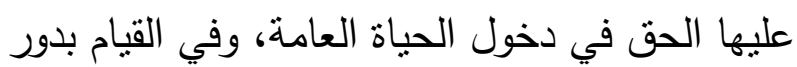

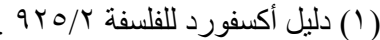

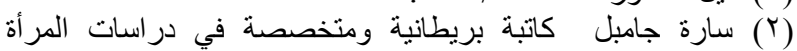

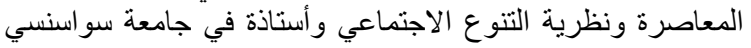

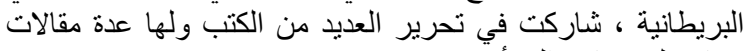

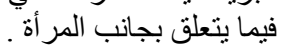


البدايات التقرييية، وهذا يقال في النظرية النسوية وفي غيرها، وعلى هذا فإنه يمكن اعتبار الحركات الحقوقية المطالبة بالمساواة بين الرجل والمرأة والتي كانت في القرن التاسع عشر (') بداية الظهورات بلهن الأولى للنسوية، حيث ظهرت كحركة منظمة تطالب بايجاد القوانين والتشريعات التي تساوي بين المرأة

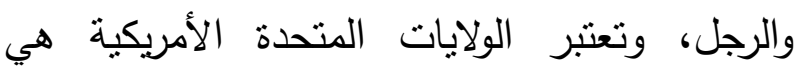
الشرارة الأولى التي انطلقت منها قضايا حقوق المرأة،

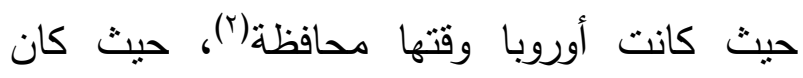
الظهور الأول للنسوية منشغلاً بقضايا التعليم والتوظيف وقوانين الزواج ومحنة بنات الطبقة الوسطى، ولم تكن الحركة مهتمة أساساً بمشاكل

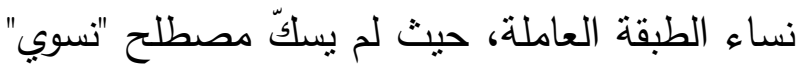
إلا في عام 190 (م، وكانت النسوية في وقتها

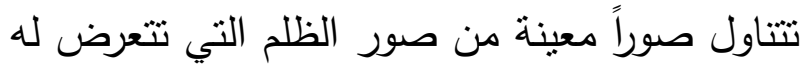

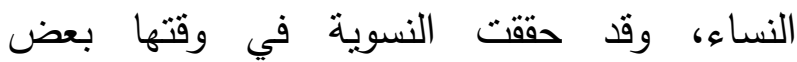
الإنجازات كتحقيق شيء من المساواة بين المرأة والرجل في التشريعات لكن ليس كلها، حيث منعت ملهاه من حق التصويت في الاتتخابات واستمر ذلك حتى لتى

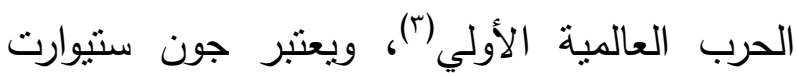

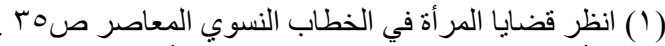

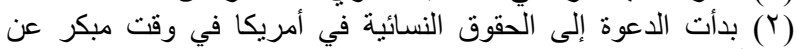

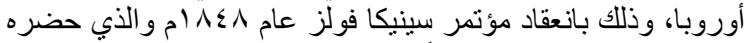

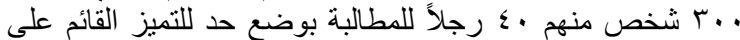

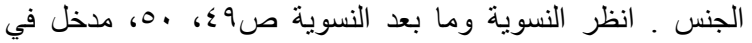

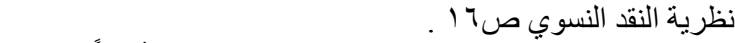

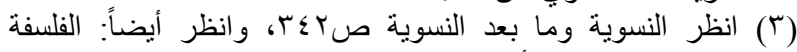

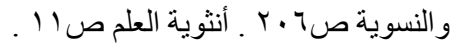

وعلى مدى العقود المنصرمة تعددت مظاهر الاتجهات النسوية في تحقيق الهذف العام الذي تتشده هذه الاتجاهات بعمومها مع اختلافها ببعض المضامين الجزئية وإن كانت في الأعم الأغلب تسير لهاه باتجاه موحّد، وهذه الظهورات النسوية اختلفت بناء على المراحل العمرية للاتجاه النسوي بشكل عام من جهة ؛ وبناء على المناخ الفكري والفلسفي التي لهني تمظهرت فيه هذه النسويات في عموم مراحلها قرباً وبعداً عن القضايا الفلسفية واستفادة من التبارات النقدية الحديثة من جهة أخرى، ولذلك ليس هنالك حركة نسوية واحدة أو فلسفة نسوية واحدة يمكن اعنبارها الناطق الرسمي باسم النسوية ؛ بل هناك مجموعة غير قليلة من الاتجاهات النسوية المتعدد تتنمي إلى أيديولوجيات وفلسفات مختلفة فهناك الفكر

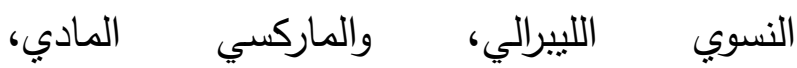
والراديكالي،والاثتراكي، والفكر النسوي لحركة السود

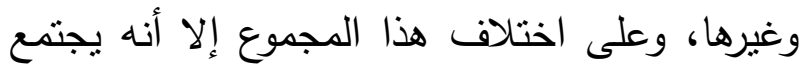

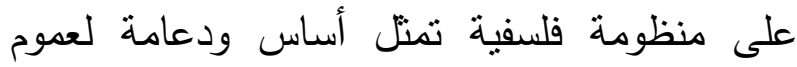
الأفكار والمقولات النسوية وهو ما يحاول البحث استكثنافه، ولكن قبل ذلك لابد من المرور السريع على أهم ظهورات النسوية في العقود المتأخرة: الظهور الأول للنسوية: في الأفكار ليس هناك بدايات ونهايات محددة تحديدياً دقيقاً كما هو الحال في الحوادث التاريخية، ولكن يمكن التحديد بالإثارة إلى أهم اللحظات التاريخية الظاهرة التي يمكن أن تُصنّف بأنها 
المفاهيم الأبوية، كما صدر كتاب "الجنس الآخر"(؟) للمفكرة الفرنسية سيمون دو بفوار(v) الذي شكل مفهوم الجندر وأصبح كما يحلو للبعض أن يسمية بإنجيل النسوية، كما صدر أيضاً كتاب "تجريد المرأة من الأنوثة"(^) و "المرأة المخصية"(9) لجيرمين غرير(·) الذي أصبح من النصوص المؤسسة الأونة للنسوبة.

ومن خلال مراقبة الظهور الثاني للنسوية، فإن النسوية تجاوزت كونها حركة إلى كونها فلسفة، لذلك فالنسوية هي فلسفة نقدية لا توضع إلا في هذا السياق النقي، ولذلك ارتبط الظهور الثاني للنسوية بفلسفة ما بعد الحداثة التي هي في العموم موقف نقدي، واشتهر في وقتها ما يُسمى بـ"النقد النسوي" وهو :" النقد الذي يصف تصوير المرأة في النصوص

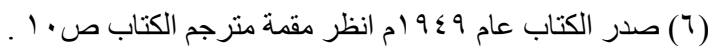

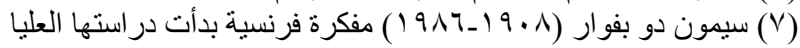

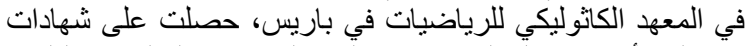

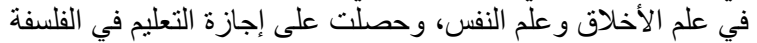

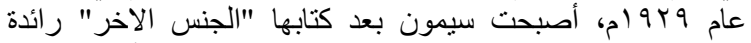

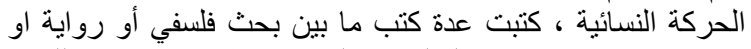

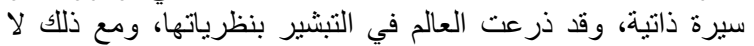

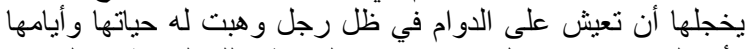

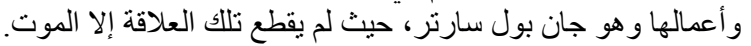

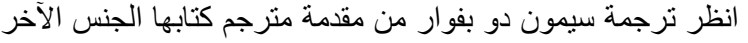
صه . نطر تئ.

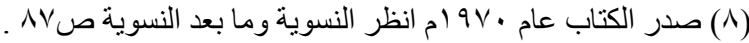

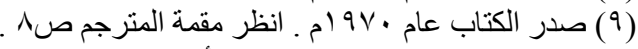

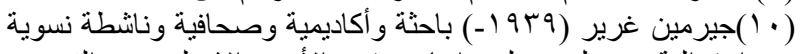

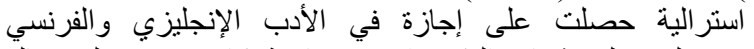

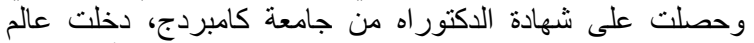

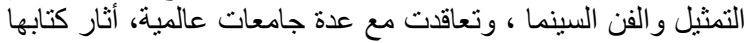

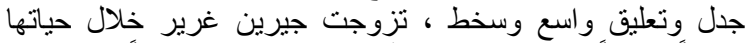

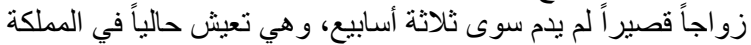

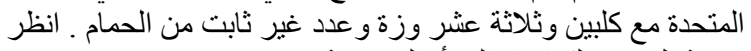

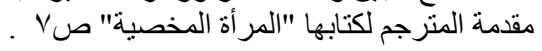

مل(') هو أبرز من تبلورت على يديه المطالبة

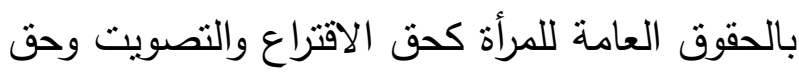
الوظائف العامة(؟). الظهور الثاني للنسوية: بتزايد النشاط النسوي في سنينات القرن العشرين في أمريكا وبريطانيا من خلال حركة الحقوق المدنية

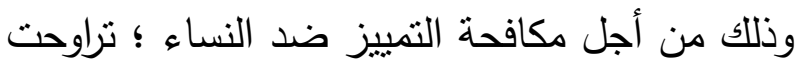
التكتيكات العديدة التي استخدمتها النسوية في هذه المرحلة ما بين الدعوة المحاطة بالدعاية الضخمة أو لهوني

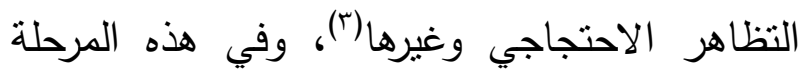
تجاوزت الحركات النسوية مسألة المساواة بين المرأة والرجل إلى تكوين مفاهيم عن المرأة وإعادة النظر في المفاهيم المتوارثة كمفهوم الأنوثة وغيرها، وهذا أبرز ما يميز الظهور الثاني للنسوية، وفي هذه النهائه المرحلة باللذات بدأت بعض المقاتلات النسوية

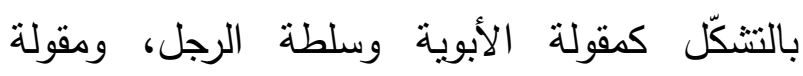
الجندر، وفي هذه المرحلة صدر كتاب أصل العائلة

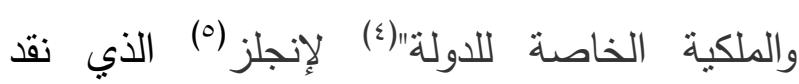

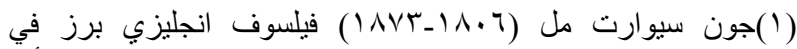

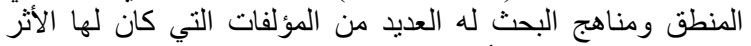

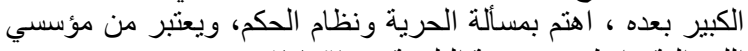

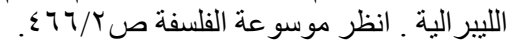

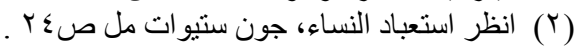

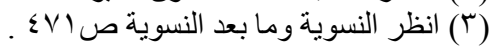

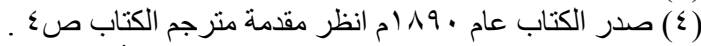

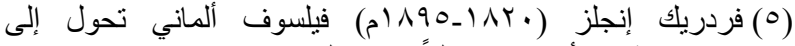

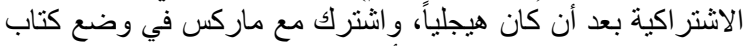

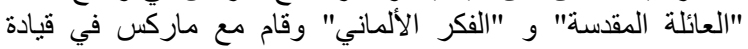

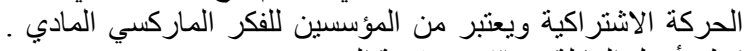

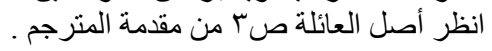


تتصدر القضايا المحورية في الدراسات النسوية سواء كان ذلك على مستوى النظرية أو على مستوى التطبيق والواقع العملي هي إثكالية "المصطلح النسوي" حيث تجري إثكالية المصطلح في الفكر النسوي كما تجري في أي حقل من حقول الفكر والثقافة، لكن الإشكالية تزداد تعقبداً بالتزايد المطرد بقضية المرأة انطلاقاً من صدى الضغط على أيقونة حقوق الإنسان بوصف أن المرأة كائن يرسف تحت التمييز الذكوري ويفتقر إلى كثير من حقوقه التي لا تجعله إنساناً مساوياً للرجل بصفة تامة .

إن إثكالية المصطلح في الخطاب النسوي هي جزء من إثكالية المصطلح في الفكر العربي عموماً، وربما تكون إثكالية المصطلح النسوي من أشد المصطلحات الثقافية تعقيداً، نظراً لكون قضية المرأة قضية ثقافية يدخل فيها البعد السجالي الأيديولوجي بدرجة كبيرة، يغذي ذلك صراع الأطراف المتنازعة لكسب مواقع اجتماعية تكون فيها المرأة ميداناً للصراع، وإن كان الصراع في الأساس أكبر من قضية المرأة، وربما يصح القول إن الصراع بين الإسلام والعلمانية هو الأساس وما إثكالية المصطلح النسوي إلا ميداناً من ميادنه .

إن المصطلح النسوي يمتذ من الأساس الفلسفي للنسوية، مروراً بالمصطلحات الثرعية حضوراً وغياباً كمصطلحات "الأسرة" و "اللباس" و "الزينة" وغيرها وانتهاء بالمصطلحات النقدية أو ما يسمى بالنقد
التي يكتبها الرجل، وبهنم بكيفية دراسة تأثير الجمهور بالصور الاختزالية أو الإقصائية للمرأة"(')لذلك كان المنطلق الأساسي للنسوية هو رفض المركزية الذكورية والقيم الذكورية التي صبغت الرؤى المعرفية، وإن كان هناك تعدد في اتجاهات النسويات إلا أنها تتفق على هذا المنطلق . وتقسيم مراحل ظهور النسوية لا يعني انحسار مرحلة أمام المرحلة التالية، بل هناك تتداخل بين هذه المراحل، حيث تطور النسوية إلى دخول مرحلة المجال الفلسفي، وصياغة المفاهيم المتعلقة بالمرأة لا يعني توقف الحركات التحررية المطالبة بالمساواة والحقوق العامة كما لا يخفى . المبحث الثاني: إثكالية المصطلح في الدراسات النسوية في الفكر العربي المعاصر

إن التطور السربع خلا العقود الثلاثة الماضية للنظربات النقدية انعكس بصورة تلقائية على الفكر المتعلق بالمرأة فيما أطلق عليه مؤخراً بالفكر النسوي، والذي بعتبر فرع من فروع النقد الثقافي الذي يتتاول بالنقد والتحليل الأنساق التقافية والبُنى الاجتماعية الذي نتكلت فيها المفاهيم المتعلقة بالمرأة سواء من ناحية المعتقدات أو التصورات والقيم

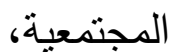
وإذا كانت الدراسات النسوية تجعل المنطلقات الغربية خلفية معرفية لها ؛ فإن من أهم الإشكالات التي (1) مدخل في نظرية النقد النسوي ص.r 
"الأنثوية"، "المساواة" غيرها إلا إنها في السياق النسوي تكون محمّلة بالدلالات التي توحي بعمومها لألوانها

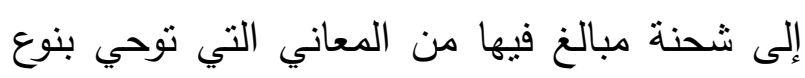

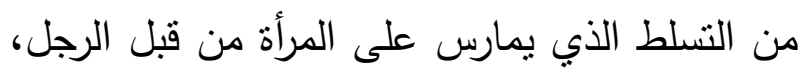
لذلك فإن كثيراً من المصطلحات النسوية لا يمكن

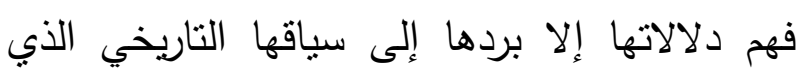
تشكّلت فيه، وكثيراً من الاستخدامات العربية لهذه المصطلحات لا يراعي للأسف ظروف تشكّل

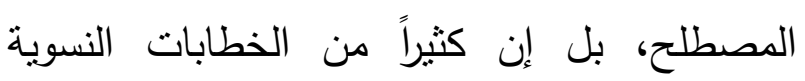

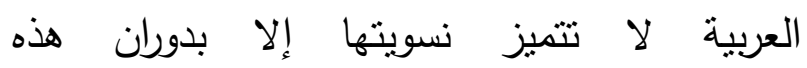
المصطلحات بين ثنايا جملها كنوع من البرهنة الثقافية للانحياز إلى صف الأنثى .

\section{المبحث الثالث: الأسس الفلسفية للفكر النسوي}

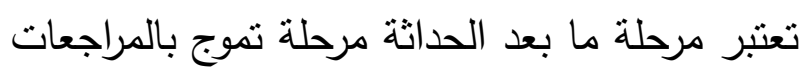

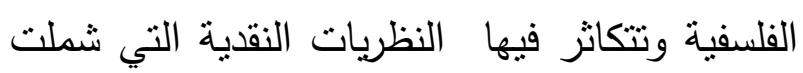
شتى مناحي التفكير الفلسفي، وانسحب ذللك على ونى عموم التصورات والمفاهيم التي كانت سائدة في مراحل سابقة، ويأتي الفكر النسوي في هذه المرحلة شديدة التعقيد التي نتابكت فيها النظريات النقدية بشكل انقلبت فيها كثير من المفاهيم والدلالات، لتعيد قراءة المرأة بشكل عام قراءة جديدة مخلّفة وراءها جملة من القضايا المفاهيمية والدلالية التي تحتاج بدروها إلى مسائلة كبيرة. إن أسس الفكر النسوي تمند لنتمل مجموعة من من النظريات الفلسفية في المعرفة والسياسة والأخلاق وغيرها من فروغ الفلسفة، ولكن ما يهر هذا البحث
النسوي، وتدخل الإشكاليات المصطلحية هنا دخولاً

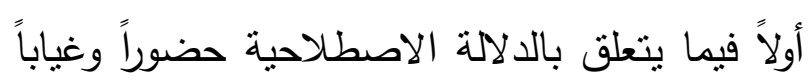

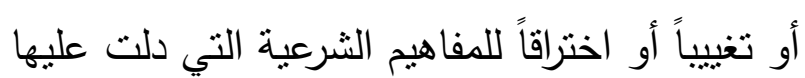
النصوص الثرعية بفهم سلف الأمة .

إن عموم إنتكالية المصطلح النسوي لا تخرج عن إثكالية المصطلح في الفكر العربي المعاصر فهي إنهاليه

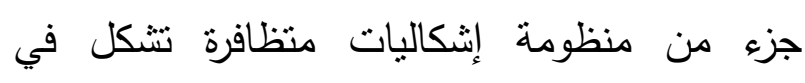

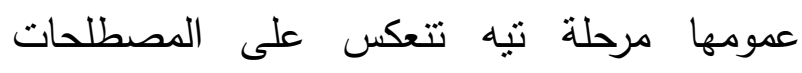
الثرعية مُموهة لدلالتها ومفاهيمها، وقد يكون الأصل الفلسفي للفكر النسوي أساساً جوهرياً في إثكالية المصطلح النسوي في الفكر العربي المعاصر، لذا هان

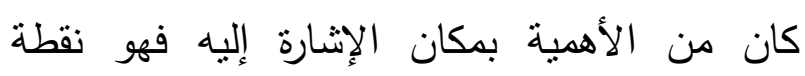

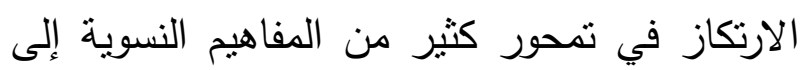
دلالات لا تتفك عن المكوّن الغربي كما سيأتي بيانه

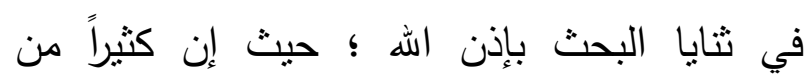
المصطلحات المتداولة في الخطاب النسوي والتي لني تعمل بشكل فعّال في إحلال دلالات معينة واستبعاد

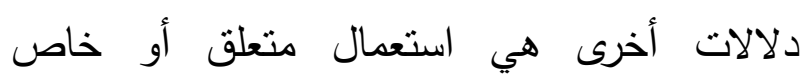
بسياقات معينة، حيث تئكد هذه السياقات بعموهها دور السلطات التي تمارس على المرأة بصفتها امرأة

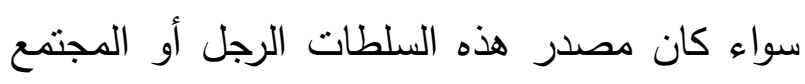

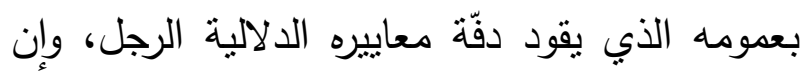

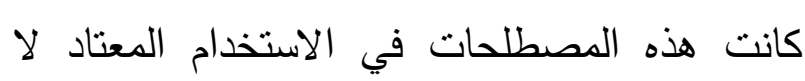

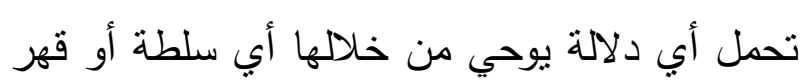
يمارس على المرأة، ومن تلك المصطلحات: "القمع"،

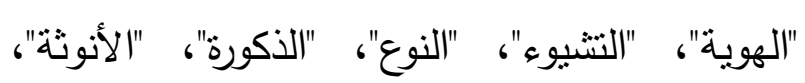


الحق الأمّي كان هزيمة تاريخية عالمية للجنس النسائي، فقد أخذ الزوج دفة القيادة في البيت أيضاً، وحرمت الزوجة من مركزها المشرف، واستذلت، وغدت عبدة رغائب زوجها، وأمست أداة بسيطة وهنة لإنتاج الأولاد، إن وضع المرأة المذل هذا الذي يظهر ببالغ السفور عند يونانيي العصر البطولي وبسفور أثند عند يونانيي العصر الكلاسيكي .. وما إن أقرت سلطة الرجال بوجه الحصر على هذا النحو، حتى أخذ مفعولها الأول يتبدى في شكل انتقالي ظهر آنذاك، هو شكل العائلة البطريركية (الأبوية) إن فئي الميزة الرئيسية التي تتميز بها هذه العائلة ليست تعدد

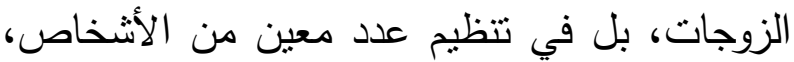

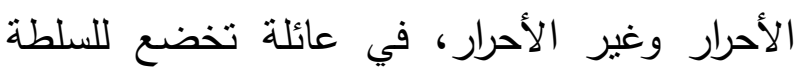

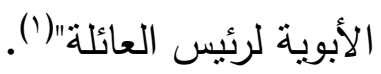

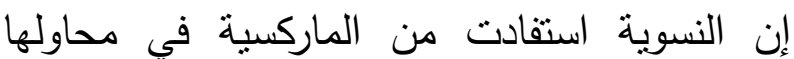
تفسير اضطهاد الرجل للمرأة، وأن هذا جزء من الصراعات الطبقية، وأن دونية المرأة هي نتيجة التطور التاريخي للمجتمعات ولا تتعلق بالفروق البيولوجية بين الرجل والمرأة، وأن دور النسوية كفلسفة هو رد الوضع الإنساني كما هو قبل نشوء

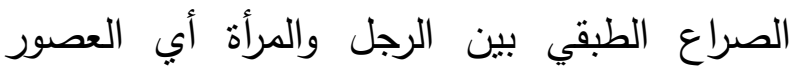

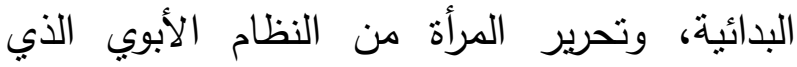
يعتبرها آلة للإنتاج فقط، ولذلك فإن دفاع الماركسية عن المرأة يأني في سياق تأكيد مقاومة الصراع

( (1 انظر أصل العائلة والملكية الخاصة والدولة، فريدريك إنجلز صیى
بالذات هو الجانب المعرفي وكيفية نشكّل الدلالات تجاه الأنثى، وما رافق ذللك من حركات نقدية ساعدت على تبلور كثير من المقولات النسوية، حيث إن ميلاد الفكر النسوي بالذات في هذه المرحلة المتموجة وفي هذه المرحلة الزمنية بالذات لا يمكن

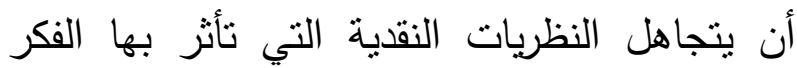
النسوي أو الفلاسفة الذين استفادت منهم الحركات النسوية في صياغة فلسفتها والتي يمكن اعتبارها جزء من الحركة النقدية في مرحلة ما بعد الحداثة،

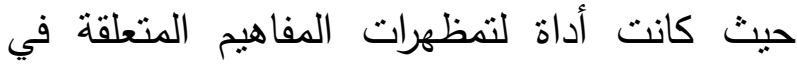
قضايا المرأة، ويمكن الوقوف على أهم النظريات النقدية التي كانت فيما بعد جزءً من البُنى الفلسفية للفكر النسوي كما في الفقرات التالية:

\section{المطلب الأول: الماركسية في خدمة النسوية}

إذا كانت الماركسية نشأت على فكرة صراع الطبقات من أجل تحسين ظروف الاتتاج وسعيها إلى تخليص الطبقات المستضعفة من استخله الطبقات العليا سواء كان سبب الاضطهاد ديني أو اجتماعي أو لطوليهات إثني، ونسجت على هذا المنوال مجمل التراث الماركسي؛ فإن النسوية استفادت من النزعة الماركسية في محاربتها للاضطهاد الطبقي واستفادت من بعض منجزات الماركسية فيما يتعلق بترتيب العلاقة بين الرجل والمرأة في نظام الأسرة، وقد يكون

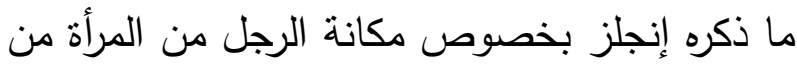

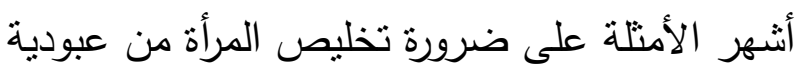
الرجل وإعطاؤها استقلالها حيث يقول: "إن إسقاط 
التتفيذ فإن أغلبية الأسر السوفيتية ستبقى بين براثن عادات القرون الوسطى والعبودية"(†) . إن الماركسية من خلال إلغاء نظام الأسرة والتحرر من القيود الاجتماعية والتشجيع على نموذج الأسرة

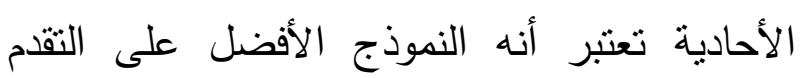

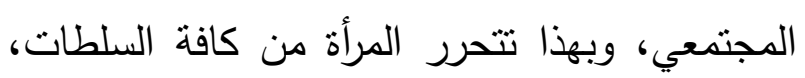
وقد أكدت المبادئ الثيوعية أن العلاقات الأسرية

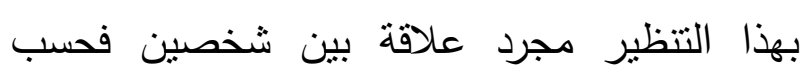
وليس للسلطات الاجتماعية أي دور في ذلك حيث ديث يعبر إنجلز عن الأثز الذي سيحدثه النظام الثيوعي الثية دئي في العائلة أنه: "سيحول العلاقة بين الجنسين إلى لى لئي علاقة محضة خاصة تهم فقط الاشخاص المعنين،

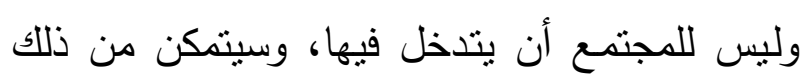

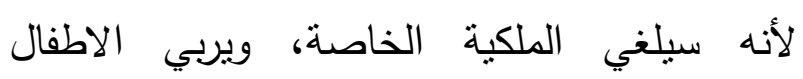

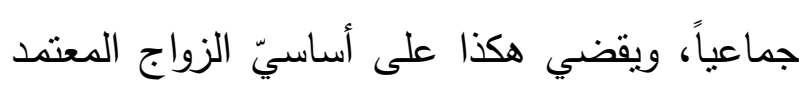

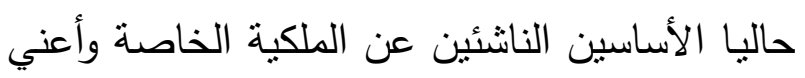

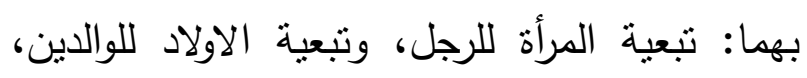

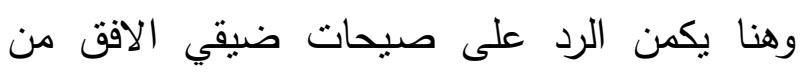
الاخلاقيين البرجوازيين ضد مشاعيّة المرأة المزعومة الفئ

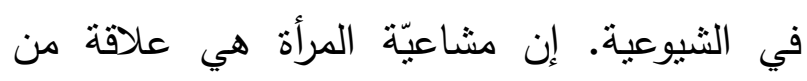

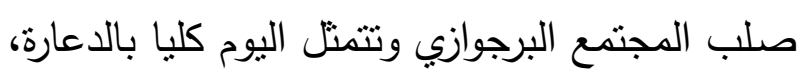

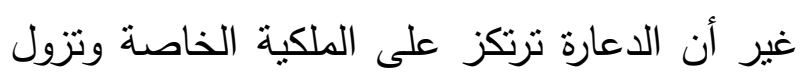

(Y) انظر الثورة المغدورة نقد التجربة الستالينية، ليون تروتسكي صrه . .
الطبقي والحد من استعباد الطبقات البرجوازية لكافة

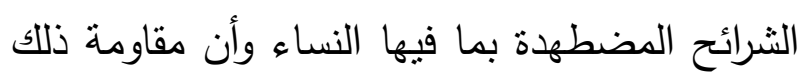

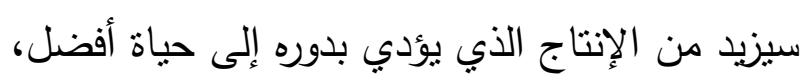

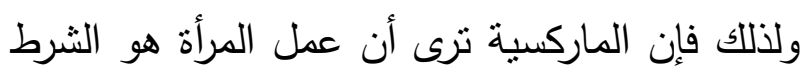

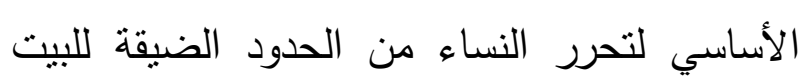
والأسرة من أجل تطويرهن ككائنات بشرية فاعلات

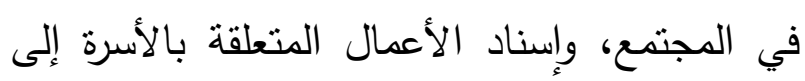

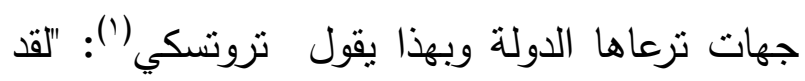
حاولت الثورة بكل شجاعة تدمير البيت العائلي الآمن

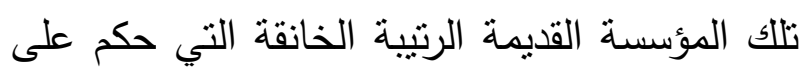

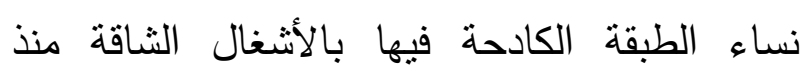
الطفولة حتى الموت، وكان الثثريون يؤمنون بضرورة استبدال الأسرة من حيث هي مؤسسة صغيرة مغلقة بنظام مكتمل الخدمات الاجتماعية: مراكز أمومة،

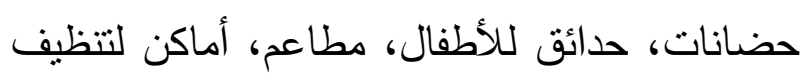
الثياب، مستوصفات، مستشفيات، مراكز للنقاهة،

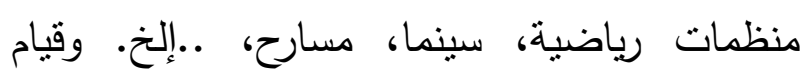

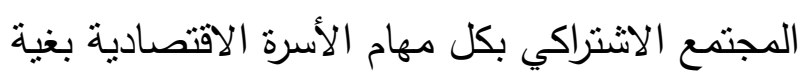
ربط الجيل كله بفكرة المشاركة والتعاون المنبادل

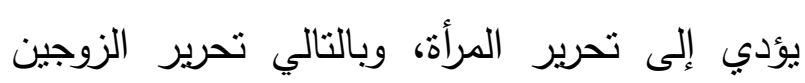

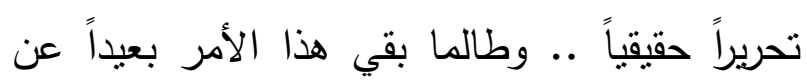

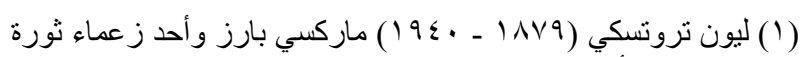

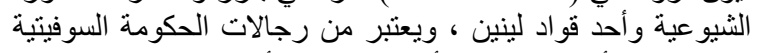

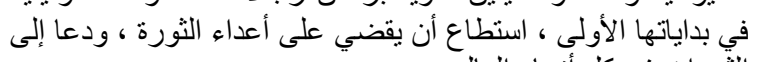
الثقر بات في كل أنحاء العالم . 
"المرأة" في الفكر الماركسي، وإنما المرأة هي فقط قوة عاملة لزيادة "التتمية" المادية . ومن هنا ظهر في كتابات النسوية الإسلامية من يجرد المرأة من أي معاني أخلاقية أو عاطفية بل يعتبر المرأة وسيلة "للتمية" أي قوة عاملة فقط لزيادة الإنتاج، وأن أي ضوابط من الرجل لعمل المرأة مهما كان يفسر بطريقة لا واعية بصراع الطبقات على المفهوم الماركسي، ولذلك كما يشجع الفكر الماركسي المرأة على الثورة ضد النظم الاجتماعية بما فيها الثورة على نظام الأسرة؛ فإن كثيراً من الكتابات النسوية العربية بدأ يدخل ضمن مصطلحاتها بعض الطرة، المضامين الماركسية والتي تؤدي بدورها إلى رفض أي وصاية على المرأة مهما كان مصدرها حتى لو كانت دينية، وقد نشأ مصطلح "ققه الطاعة" من أجل أن يوصف به الوضع الذي أوصله الفقهاء بالمرأة كما يقولون - من نشيئ(r) المرأة إلى كائن مخلوق

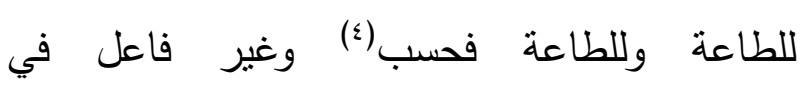
المجتمعات التتموية .

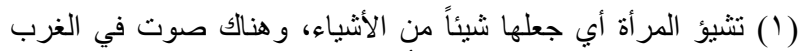

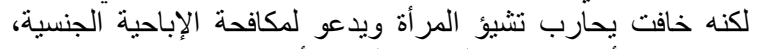

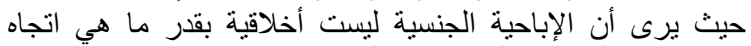

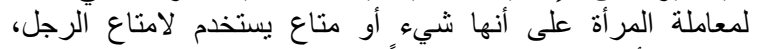

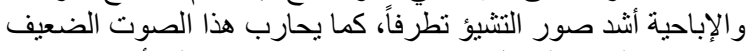

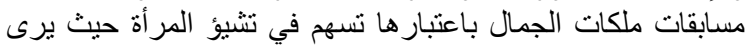

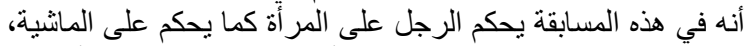

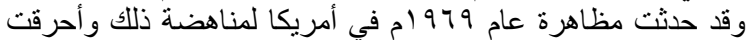

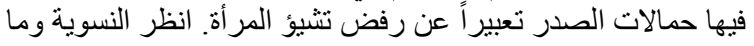

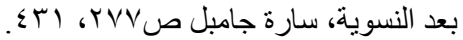

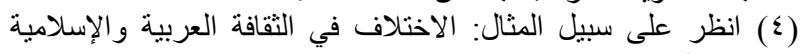

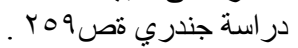

معها، فالنظام الثيوعي يلغي إذن مشاعيّة المرأة

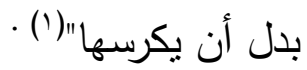
وعندما لم تتحقق هذه النظرة المثالية في المجتمع

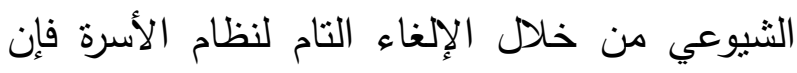
تروتسكي يفسر ذلك بأنه: "ليس هذا بسبب النعدام

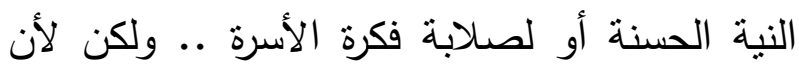
المجتمع بدا في غاية الفقر والجهل ولم تكن موارد

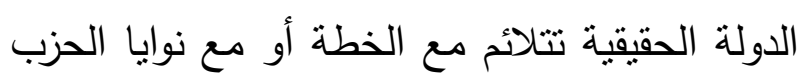

$$
\text { الثشيوعي"(؟). }
$$

إن الماركسية باتجاهها للمرأة ليس بصفتها امرأة بل

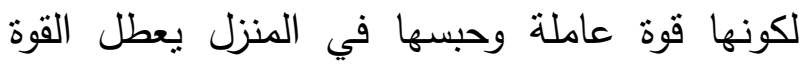
الإنتاجية، وإذا كانت الأسرة تحدّ من إنتاجيتها فإنه وله بإمكان التقدم في النظام المجتمي إلغاء الأعمال

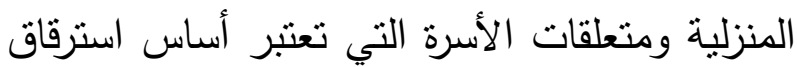
النساء، ومن هنا فإنه ليس بمستغرب حضور مصطلح "التتمية" في الخطابات النسوية كخلفية لا لانهات واعية للمنطلقات الماركسية التي تتظر إلى المرأة كما تتظر إلى الآلة أو إلى أي قوة عاملة ينبغي منحها

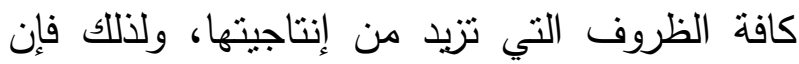
مصطلح "التتمية" في الخطابات النسوية يجرّد المرأة من أي جوانب أخلاقية سواء بصفتها مربية أو معلمة أو قدوة أو حتى الجوانب العاطفية في المرأة، كل هذا المخزون الذي تكتتفه المرأة لا يدل عليه مفهوم

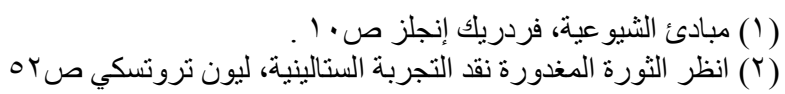


والسلطات القضائية وغيرها"(؟) والسلطة على هذا المفهوم مركبة من أمر ومن واقع اجتماعي، فكما أن السياسي له سلطة فالواقع الاجتماعي له سلطة لا له

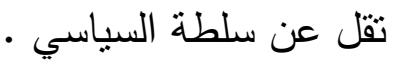

ولذلك برى فوكو أن هناك علاقة بين الحقيقة والسلطة وعلى حد تعبيره فإن: "من الوهم افتراض

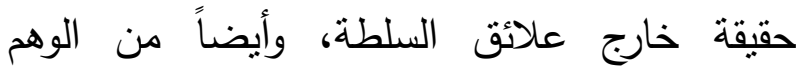

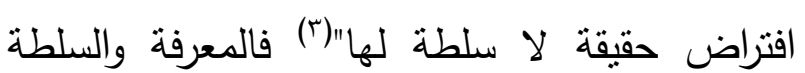
تعمل كمركب للمعرفة في نظر فوكو، ويبين ذلك بقوله:" العلاقة بين المعرفة والسلطة ليست علاقة خارجية بمقتضاها توظّّف السلطة المعرفة وتستعملها آداتياً، بل نؤكد أن تقنيات المعرفة واستراتيجيات

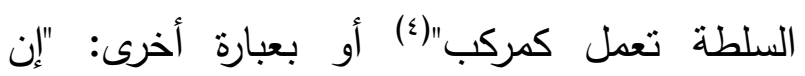
الحقيقة مرتبطة دائرياً بأجهزة سلطة نتجها بعلها

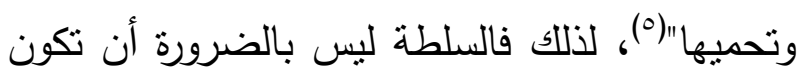

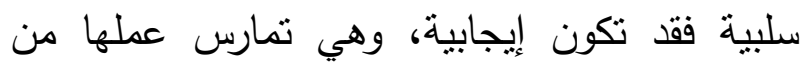
خلال القوى الاجتماعية الفاعلة، لتشكل معرفة

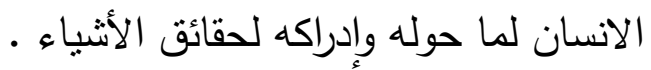

لكن فوكو يؤكد في نفس سياق السلطة والمعرفة ؛ من حيث علاقة السلطة بالقوة، فالغلبة للسلطة

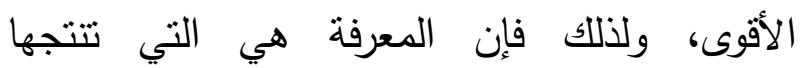
السلطات الأقوى وتسعى للحفاظ عليها ـ. وفوكو من فئ لإن

(r) انظر المعجم الفلسفي، جميل صليبا ص. •Vا، وانظر أيضاً دليل

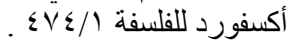

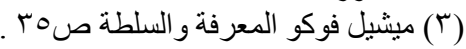

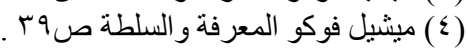

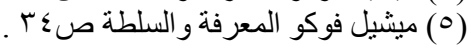

المطلب الثاني: المعرفة والسلطة مدخل جليد

\section{للنسوية}

إذا كانت النسوية في مراحل تكوينها لم تعن بشكل كبير في الجانب الفلسفي، وإنما غلب عليها الجانب الحقوقي، إلا أن المراحل الحاسمة في تاريخ النسوية تواصلها مع النظريات الفلسفية الحديثة، وخصوصاً ما اشتهر في مرحلة ما بعد الحداثة، ويمكن اعتبار

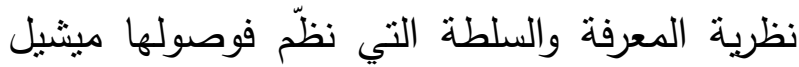

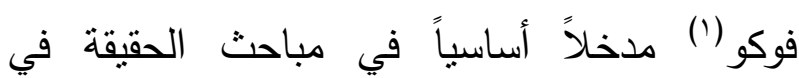
الفلسفة النسوية .

فالسلطة تتمتع بنظر فوكو بنفوذ قوي في صياغة المعرفة، وليس المقصود بالسلطة السلطة السياسية في الدولة أو بحث في علم السياسية، وإنما المقصود بالسلطة بالمفهوم الثمولي أي السلطة اللامركزية المؤثرة في الكيان الاجتماعي لإنتاج المعرفة، وفي المفهوم الفلسفي المتداول كما في المعجم الفلسفي فإن: "السلطة في اللغة القدرة والقوة على الثيء، والسلطان الذي يكون للإنسان على غيره ..

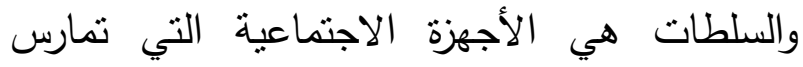

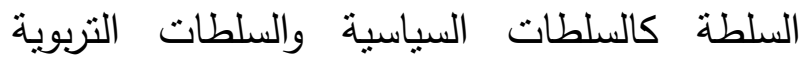

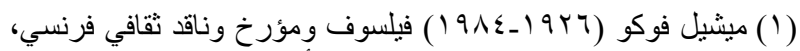

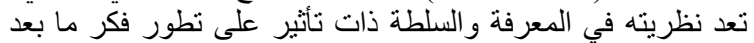

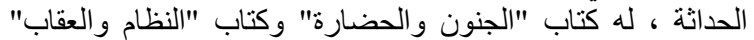

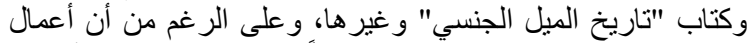

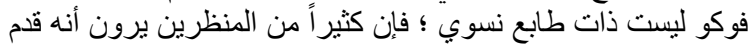

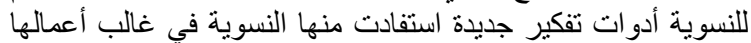

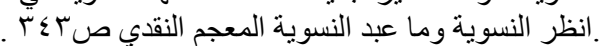


يرى مجموعة من النسويات الثقافة والقوى الاجتماعية بأنها:" أمراً أساسياً، وباعتبار أن الصورة والمعاني والرؤى التقافية تعمل على تعريف معنى المرأة والسيطرة عليها"(r) بل إن مصطلح النسوية نفسه في ملي بعض الأحيان بنطلق من فرضية أن مفهوم المرأة خضع لسلطة الرجل وتبقى مهمة النسوية في الكثف عن هذه الإكراهات، ففي مقدمة كتاب من أهم كتب النسوية وهو كتاب: "النسوية وما بعد النسوية" لسارة لجامبل افتتحت الكتاب بالسؤال التالي: "السؤال الأساسي هنا هو : ما هي النسوية على وجه التحديد ؟ الإجابة هي أن التعربف العام للنسوية يشير إلى أنها تعني الاعتقاد بأن المرأة لا تعامل على قدم المساواة -لأي سبب سوى كونها امرأة- في المجتمع له له الذي ينظّم شؤونه ويحدد أولوياته حسب روئية الرجل

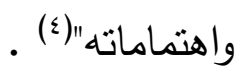

وبما أن الدراسات النسوية العربية تتطلق من أساس فلسفي غربي في صياغة مفاهيمها عن المرأة ؛ فقد تم الاستعانة بنظرية المعرفة والسلطة كما صاغها فوكو، وقد صدر في السنوات الأخيرة عدد من الدراسات والعربية تتطلق من أعمال فوكو في تقديم روئة نسوية وتهنم بمحاولة اكتثاف السلطة بين ثنايا المعرفة النسوية، ومحاولة تقديم المرأة كجنس مضطهد تمت صياغة مفاهيمه في ضوء سلطة الرجل وهيمنته، فمثلاً اعتبار اجتهادات الفقهاء عند
هذه الناحية -أي علاقة المعرفة بالسلطة - ليس معنياً بالتفريق بين الحقيقة والخطأ فهذه - كما يقول -مهمة الوعاظ الذين لديهن القدرة على الفصل القاطع بين الثر والخير ، وإنما تتحصر مهمته في كيفية إنتاج الخطاب من رحم السلطات ('). وإذا كانت المعرفة في نظر فوكو هي وليدة السلطة، فإن الفلسفة النسوية انطلقت من هذا الأساس في البحث عن نظرية للمعرفة، حيث ترى بعض أن النسويات أن المعرفة نشكلت بتأثر من النظام الأبوي السلطوي ولابد من إيجاد نظرية معرفية نسوية بحيث إنها: "تتطلق من وجهة نظر نسوبة بمعنى أنها تركز على خبرة المرأة، لأن الطربقة التي اعتاد الرجل أن ييني بها ما بعتبره معرفة موثوق بها هي طريقة أبوية، والسبيل الوحيد إلى المعرفة غير المنحازة عن العالم هي خبرة المرأة المباشرة"(r) . فتشكّل المعرفة يخضع بشكل كبير للسلطة -كما قررها فوكو -لذلك فإن السلطة الاجتماعية تعتبر محط الارتكاز في نقد مفاهيم المرأة السائدة وأنها مفاهيم تم انتاجها تحت ضغط سلطات معينة، فعند الحديث عن العالم الغربي وعن دور المفاهيم النسوية التي تمت صباغتها تحت نأثير سلطات معينة ؛ فإن مفهوم "المرأة" نفسه تمت صياغته وفق رؤى اجتماعية ثقافية سائدة، وتتطلق مجموعة من الأبحاث النسوية في الغرب على هذا الأساس حيث 
وما موقف النصوص الثرعية منها من ناحية الموافقة من عدمه، كل هذه التساؤلات تظل غائبة تماماً باستثناء استخعاء سلطة المعرفة عند فوكو . المطلب الثالث: التفكيك النسوي

إذا كانت الفلسفة النسوية قضية معرفية، تتطلق من أن المعرفة النسوية معرفة تشكلت في ضوء سياقات ذكورية اجتماعية قهرية، فإنه سيكون من أهم أوليات

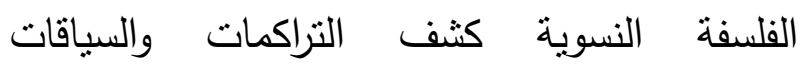
الاجتماعية التي تأثرت في تكوين البُنى المعرفية التي منها يتعامل المجتمع مع المرأة وتتعامل المرأة بها مع نفسها، ولذلك فإن صعود التيارات النسوية في مرحلة ما بعد الحداثة كان وقتاً مناسباً للاستفادة من تفكيك الفيلسوف الفرنسي جاك دريدا(ّ) فإنه بعد أن طرح المفكر الفرنسي جالك دربدا مقولته في التفكيك التي تُصنّف أنها منهجاً في استراتيجية القراءة، وذلك من خلا الإبحار داخل النص وتوجيه الأسئلة وإثارة الإشكالات بغية تقويض النص وإعادة كتابته من جديد وذللك للوصول إلى درجة من المعنى صالحة للاستعمال ولو مؤقتاً بعد استبعاد كل القراءات الأخرى، حيث إن القراءة التفكيكية هي: "قراءة مزدوجة تسعى إلى دراسة النص مهما كان

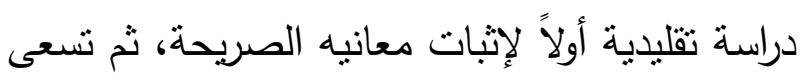
إلى تقويض ما تصل إليه من نتائج في قراءة

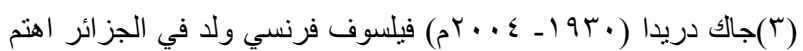

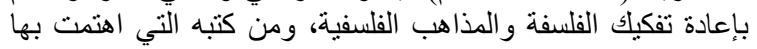

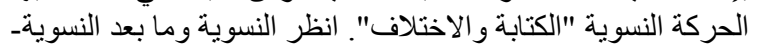

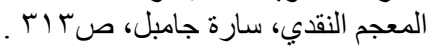

بعض المعنيين بالقضايا النسوية بأنه نوع من ممارسة سلطة الفقهاء لفرض نوع معين للمفاهيم النسوية تخالف الإسلام - على حد تعبير بعضهم كما في نص نبيل فياض قوله: "في المعركة ضد المرأة راح التطرف الديني يحاول بعث الحياة في مومياءات عصور الانحطاط، وإعادة تلميع نتاجها الفكري الذي علاه الصدأ، ورحنا نشهد كرنفالاً احتفالياً لتسويق منتجات ابن تيمية وفتاويه المتعلقة بالمرأة، أو تسليطاً للضوء على آراء خاصة جداً في المرأة تعبر عن مرحلة معينة لعلامة كالغزالي، ومحاولة تعميم تللك الآراء على النساء في كل الأزمنة والعصور "(') وهناك نصوص كثيرة في عموم قضايا المرأة ليس هذا مجال بحثثا كقضايا الحقوق أو اللباس والزينة وغيرها نشير تلك الدراسات أن كثير من المفاهيم فيها لم تكن ناطقة باسم الثرع وإنما تمت صياغتها وفق سلطة المجتمع ومنطوق

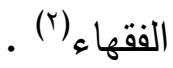
وعلى هذا فإننا نجد منهج ما يسمى بالنسوية الإسلامية استعار فلسفة فوكو في السلطة والمعرفة، وجعل القضايا التي لا تتناسب مع أطروحاته أُنتجت بظروف سلطوية ذكورية من خلا التراث الإسلامي دون مناقشتها علمياً، وإنما الاكتفاء بتصفيتها معرفياً دون الدخول في تفاصيل القضايا وكيف تم بناؤها،

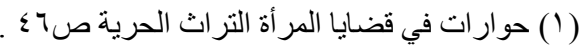

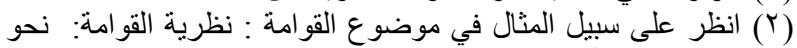

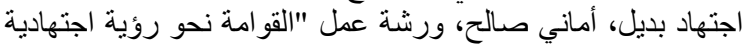

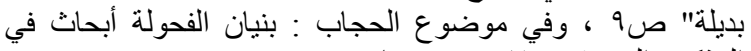

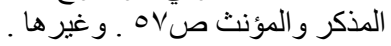


ودور الفلسفة التفكيكية هي تقويض هذا الخداع والبناء من جديد لتصورات نرى النسوية أنها

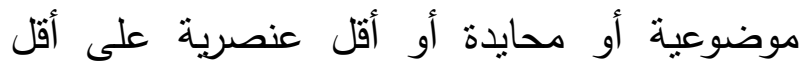
تقدير ولذلك يركز البرنامج التفكيكي الذي تنبته النسوية في

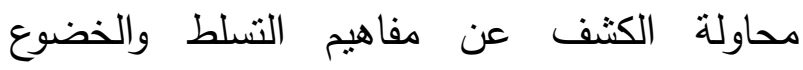
الأيديولوجي الممارس على المرأة، وإعادة تقويض وله نظام المعرفة الذكورية، وذلك بنقد المقولة القائلة بأن التفاوت في الجنس هو أساس اللامساواة بين النساء

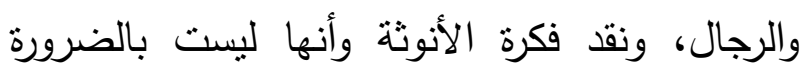

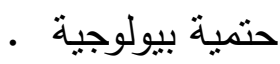

إن أهم ذراع من أذرع الفلسفية التفكيكية التي لئوليه استعملته الاتجاهات النسوية هو نقد التمركز وفكرة الحضور والغياب والتي أكد عليها دريداً في صلب التهركي مباحثه النقدية، ويعني بالتمركز أي منح فكرة ما أولوية وأسبقية على غيرها، وهذا بدوره يؤدي إلى بلى بلى بلى بلى المبالغة في حضورها، ومن ثم غياب الأفكار الأخرى الموازية لها بحيث تصبح في دائرة المهشه، وقد ذهب دريداً في تفكيك مجموعة غير قليلة من فن فئن التمركزات القارة في الفلسفية الغربية من أفلاطون وأرسطو إلى العصر الحاضر، ك"التمركز العقلي" و "التمركز العرقي "و "التمركز الصوتي"، وقد استفادت التئ

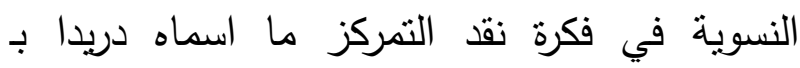
"التمركز القضيبي" والذي يعني فيه: "تكريس هيمنة
معاكسة، تعتمد على ما ينطوي عليه النص من معانٍ تتتاقض مع ما يصرح به، وتهدف القراءة التقويضية - أو التقكيكية - من هذه القراءة إلى لى لهن إيجاد شرخ بين ما يصرح به النص وما يخفيه، بين ما يقوله النص صراحة وبين ما يقوله من غير تصريح "(') والهدف من هذه القراءة التفكيكية استبعاد ما كان سائداً من مفاهيم ودلالات حول المرأة، وإحلال معانٍ ودلالات جديد عنها لم تكن حاضرة في وقت سابق، وقد كانت المنهجية التي أطلق عليها دريدا مصطلح التفكيك باباً يعتبر الباب الأكبر

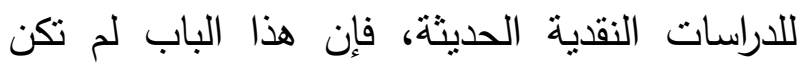
النسوية بمغفل عنه وخصوصاً في الدراسات النسوية

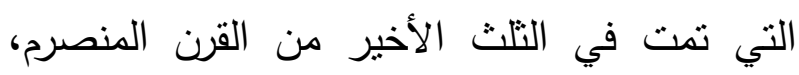
حيث بمنل التفكيك آخر صرعات النقد الحديث. وإذا كانت الدراسات النسوية تهدف بالأساس إلى تغيير الدلالات المرتبطة بالمرأة والتي ترى أنها

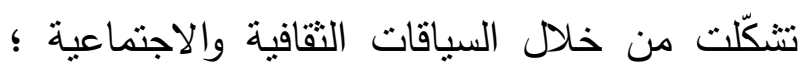
فإنها بحاجة إلى عُدة منهجية قادرة على الحفر والتققيب، ولذللك كانت الفلسفة التفكيكية هي المرشح

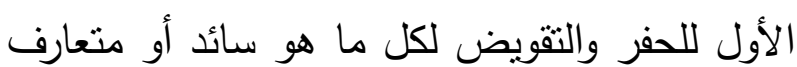
عليه مما عَدّته الدراسات النسوية ترسّبات اجتماعية وثقافية أفرزت مجموعة من الدلالات تختصر المرأة بدور مهمّش داخل المجتمع وتخلع عليه مصطلحات ذات أبعاد دونية وذلك بفعل السلطة الاجتماعية، لاعل 
بامنياز في هذا الجانب لأن قضية التفكيك الأولى هي الكثف عن الحضور والغياب داخل المتقابلات: الذكر / الإنثى، خير / شر، ظاهر / باطن، واقعي

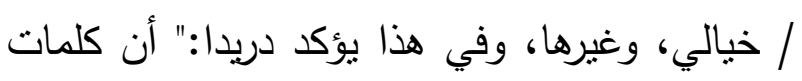
من هذا النوع نوضح بصورة أفضل من غيرها، وفي هوكال الأماكن الني يعجز فيها المقال عن السيطرة والحكم

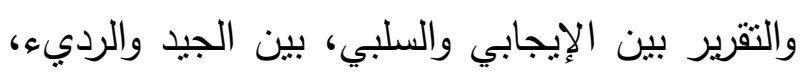
الحقيقي والمزيف، من هنا كانت محاولة إبعاد هذه

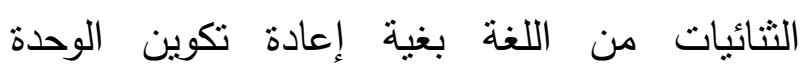

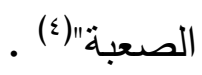

ما سبق يبين أن الفلسفة التفكيكية قدمت دعماً نقدياً

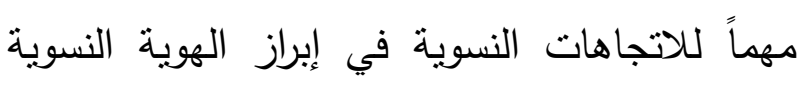

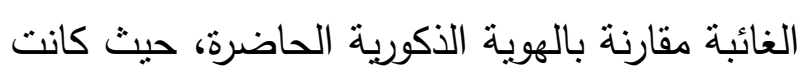
ثلاك الذكورية محط انحياز الدلالات الإيجابية مقارنة بالآخر الغائب/الأنثى الذي نوارت دلالاته وهويته،

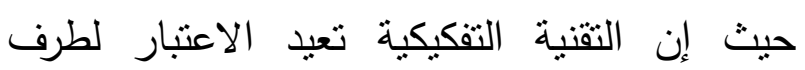

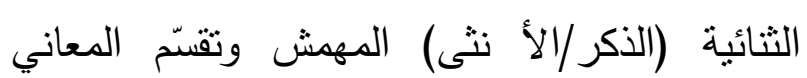

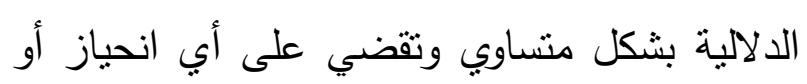
تمركز ذكوري يؤدي إلى تغييب الآخر أو إقصائه . المبحث الرابع: امتدادات الأسس الفلسفية للنسوية

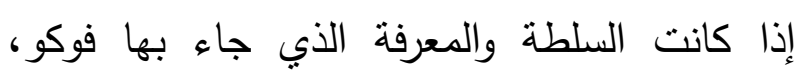
والتنكيك الذي دشّنه دريدا كمنهج في قراءة النصوص وله

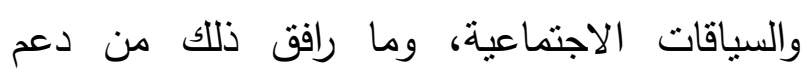

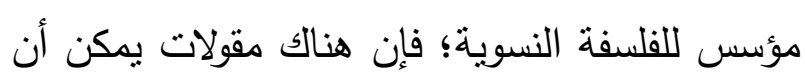

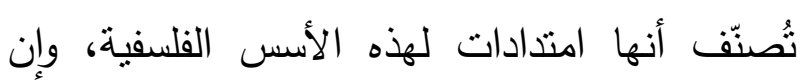

( ) التفكيكية ار ادة الاختلاف وسلطة العقل، عادل عبد اله ص بو .
الذكور والإقرار بدونية النساء"(') حيث يشخص دريدا موضوع "التمركز حول القضيب" وذلك: "برصد بلديه

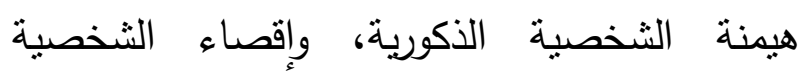
الأنثوية، وكأن المعيار في الإقصاء أو التكريس من

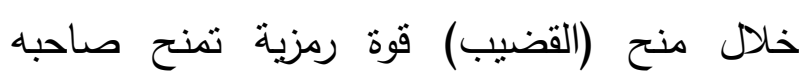

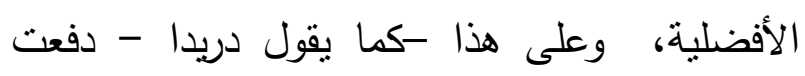
الميتافيزيقا الذكر إلى واجهة الاهتمام بسبب امتلاكه هذا العضو فيما أقصيت المرأة وجرى تغييب دورها لافتقادها إلى ذلك العضو تحديداً، وهذه التمايزات المبنية على فكرة التفاوت والمفاضلة أدت إلى إقصاء

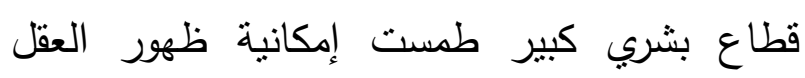
والتقافة فيه"(؟) ويعتبر كثف التحيز هذا مطلب من طن مطالب النسوية، حيث إن المرأة حسب ثنائيات دريدا تبقى آخراً بالنسبة للرجل، بل غائباً أيضاً مقارنة

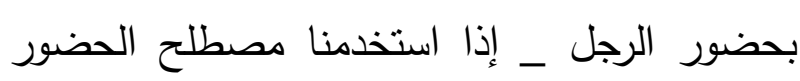
والغياب الدريدري - ولذلك فإن هويه الآخر/المرأة هذه لبست هوية متجسدة/حاضرة، وعلى هذا فإنه يصعب تحديد هوية لا تمنلك حضوراً متحققاً، ودريدا يؤكد هنا: "أن الآخر موجود ولا سبيل إلى إلغاء لهاء

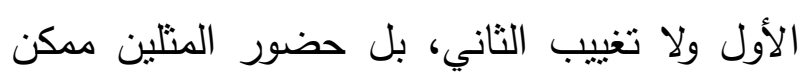
دائماً دون ثمة ضرورة لإلغاء طرف من أجل

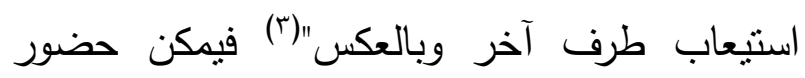
الآخر بهوية كاملة التحقق، ودور الفلسفة التفكيكية تأكيد حضوره لا تهميشه، ودريداً هنا يقدم دعماً نقدياً

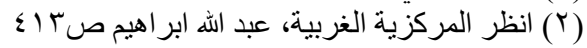

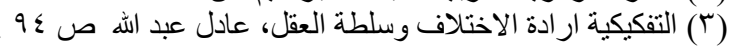


إن الأنوثة على مقولة الجندر معطى ثقافي وليس

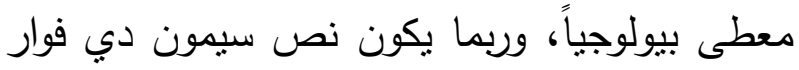

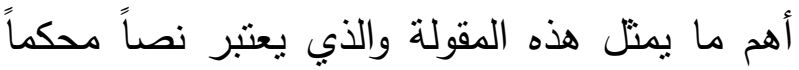

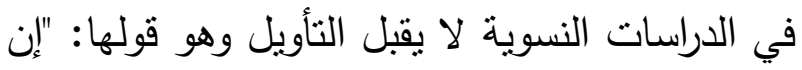

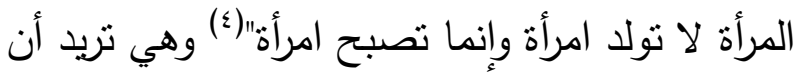
تتوصل إلى أن المرأة ليس لها جوهراً أبدياً، بل ناريخ

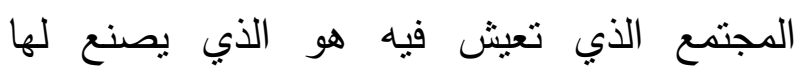
التجويف أو القالب الذي ستعيش فيه، ولذلك انطلقت الخطابات النسوية تؤسس لهذه المقولة، ونقد الحتمية الأنثوية التي تقلل من قدرة المرأة على الانتاج، وأن

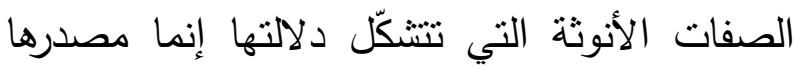
النقافة المجتمعية، ليس هناك صفات ثابتة للأنوثة، وقد استفادت الخطابات النسوية النقدية باستخدام التقنية التفكيكية بتقويض البنُى الاجتماعية والثقافية التي أسهمت في بناء شخصية للمرأة ومفاهيم ذات التهاته

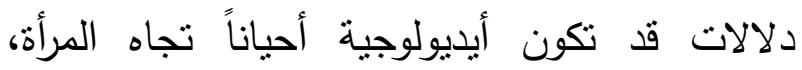
والعودة إلى النوع مجرداً عن أي إضافات أيديولوجية التهاه أو إكراهات اجتماعية قسرية . وقد اتجه أغلب الباحثين الغربيين على أن الجنوسة إنهاكة (الجندر ) ليست بنية طبيعية وليست حتمية بيولوجية

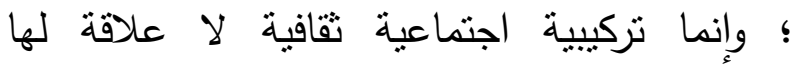
بالتكوين الجنسي البشري وقد حاولوا رصد صيرورة الدور الفعال الذي تلعبه الجنوسة، ويذهب دارسوا الجنوسة إلى أن الفرق بين "الرجل" بصفاته الإيجابية

(§) انظر شرح لهذه المقولة في كتاب الجنس الآخر، سيمون دو بوفوار

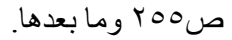

كانت متداخلة معها من حيث الأوجه، ولكن لأهميتها ولكثرة دورانها في الخطاب النسوي كان إفرادها بسياق خاص مؤكداً على أهميتها وجوهرية اشتغالها في الخطاب النسوي • وهي: مقولة "الجندر" ومقولة "البطريركية" والحديث عنها من خلال الآتي: المطلب الأول: الجندر

قد يكون مصطلح الجندر (Gender=نوع/جنوسة) من المصطلحات المفصلية في الأبحاث النسوية "وهو المصطلح الذي صاغة عالم النفس روبرت ستولر (')((') حيث إن الجندر لا يعني الجنس، فإذا

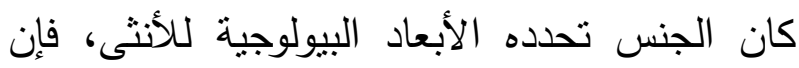

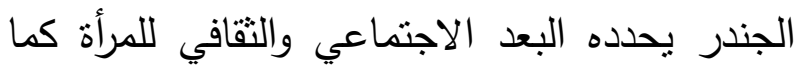
هو تعبير سارة صوفيا فوكا بأن:" الجنس هو الذي لإني تحدده الكروزومات أي المادة الخام، وهو ثابت لا لان يتغير ويقوم على أسس بيولوجية، أما النوع فهو فكرة راسخة في البنية الثنائية وتقف وراءها، وليس هناك أي علاقة بين النوع وبين الجنس"(ז) فالأنثى مسألة ولئ جنس وتثتير إلى كائن يحمل مواصفات معينة منل

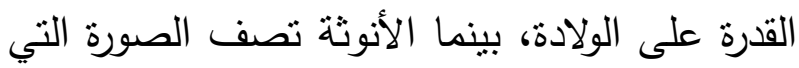
يكوّنها المجتمع عن المرأة، لذلك فالأنوثة مسألة ثقافة وليست مسألة جنس .

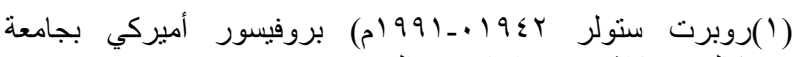

$$
\begin{aligned}
& \text { كاليفورنيا اثتنهر بدراساته عن الجندر . }
\end{aligned}
$$

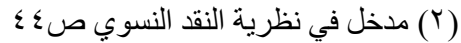

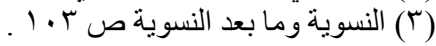




\section{المطلب الثاني: البطريركية/الأبوية}

تعتبر البطريركية أداةً جوهرية في الدراسات النسوية

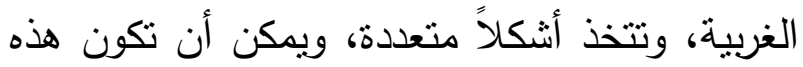
الأداة من أهم الأدوات التي يكثر دورانها في لهني الدراسات النسوية الغربية، وإذا كانت مجمل الدفاهيم التي تم صياغتها عبارة عن نتاج القوى الاجتماعية والثقافية، فإن أبرز دور كان سبياً في تشكيل هذه الهفاهيم هو الرجل الذي يمارس سلطته على المرأة داخل الأسرة في الدرجة الأولى التي تعتبر من أثند لهد لهن مواطن قمع المرأة واضطهادها، ويشير مصطلح البطريركية أو النظام الأبوي إلى: "علاقات القوة التي

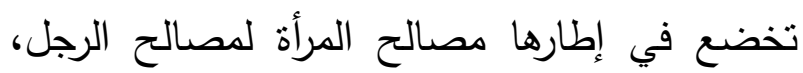

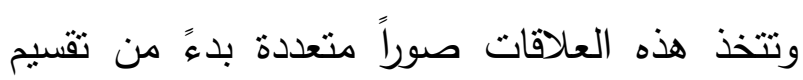
العمل على أساس الجنس والتنظيم الاجتماعي لعملية

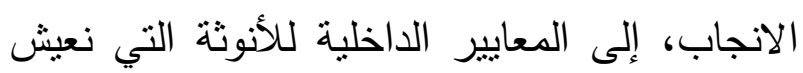

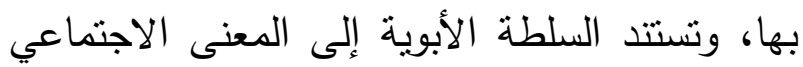

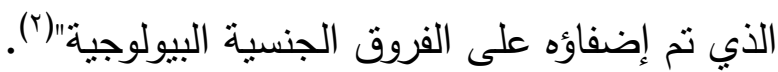

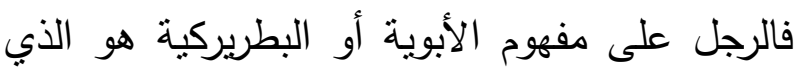

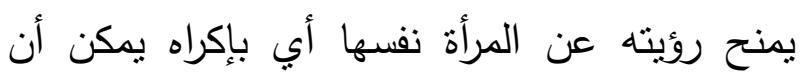

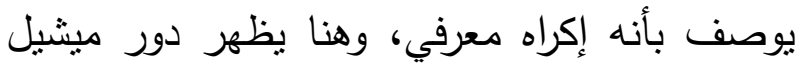

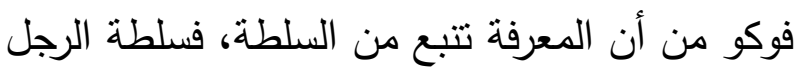
على المرأة هي التي تحدد المفاهيم المتعلقة بالمرأة وتعطيها الحق والمشروعية ليس عند الرجل فحسب الفي بل حتى عند المرأة نفسها، لذلك كان من أولئيات

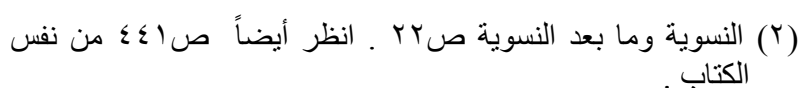

و "المرأة" بصفاتها السلبية إنما هو فرق أيديولوجي

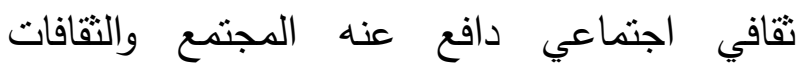
المختلفة، كما أن الضغط الاجتماعي والثقافي يؤسس

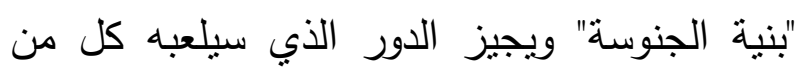
الطرفين، وبهذا فإن التقافة وليست الطبيعة البيولوجية هي التي تضع قيوداً ومحددات التفكير والابداع

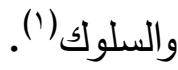
ومن خلال مقولة "الجندر" بأبعادها المعرفية، فإن الفروقات بين الرجل والمرأة قد تقترب من التلاشي باني إذا افترضنا أن أنوثة المرأة لا تحددها البيولوجيا بقدر

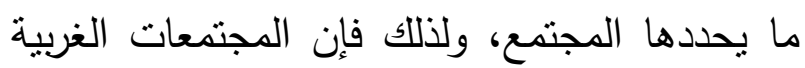
التي تتطلق في مكوناتها الاجتماعية من الفلسفية الغربية أصبحت مقولة الجندر مقولة أساسية، وفرضت نفسها حتى على الجانب التشريعي إلى حد

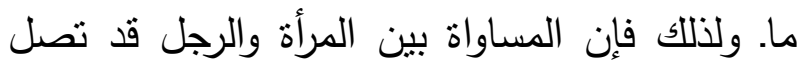
إلى حد التطابق، والفروقات بين الجنسين قد تقترب

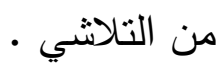

إن مقولة "الجندر" تكتسب أهميتها كرافد أساسي للأسس الفلسفية للنسوية، من حيث تسعى هذه المقولة إلى تصفية جميع السياقات الاجتماعية والثقافية التي تميز الرجل عن المرأة، بل حتى لهيه مدلولات النصوص الدينية ؛ بحجة أن هذه المدلولات تشكلت في ظروف اجتماعية لم تكن الأسس العلمية

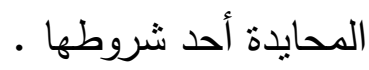

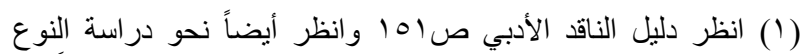

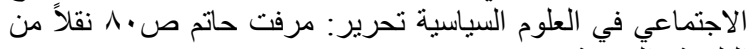


صلاحياته بفرض السلطة على المرأة بقهرها على

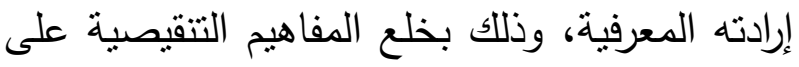
المرأة وفرض سلطته بوصفه مركز السلطة ومحور الدوران، على أن تكون هذه الدلالات وهذه المفاهيم محل اعتبار اجتماعي وقبول حتى عند المرأة نفسها.

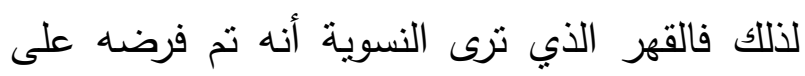
المرأة بطريقة أبوية بطريركية صار مستساغاً ومقبولاً

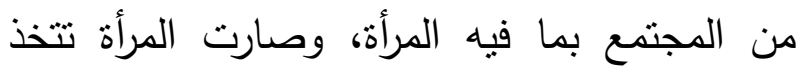
وضع الآخر من تلقاء نفسها، ونواطأت النساء

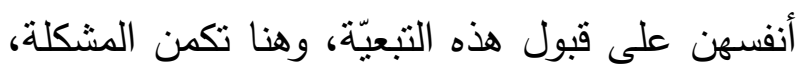
ولذلك فالنسوية ترى أن المرأة التي ندافع عن هن ناهن

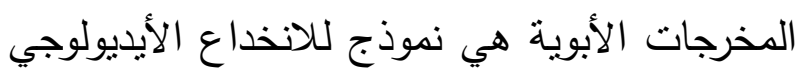
التي جعلت المرأة تتصهر في هذه الدلالات السالبة

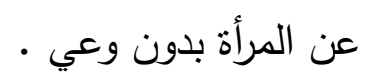

إن المقولة البطريركية لا يمكن أن تجد امتداد النداد ومشروعية لها لولا المناخ الفلسفي الغربي الذي لهني لهني

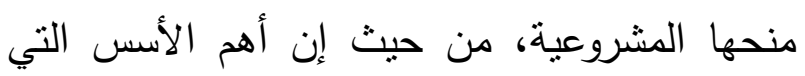

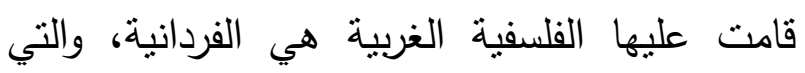
تعني في الفكر الغربي أن: "قيمة الفرد أعلى من قيمة المؤسسات المحيطة به، لأن الفرد هو الغاية

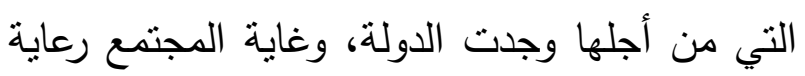
مصلحة الفرد"(")، لذلك دفعت النظريات الغربية المرأة إلى الاستقلال عن الرجل، ووصفت الأسرة

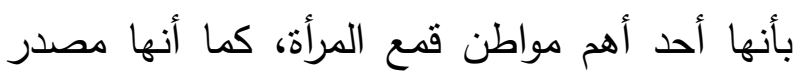

(T) المعجم الفلسفي، جميل صليبا // إ ا . .
النقد النسوي تفكيك هذه الإثكالية وكثف نوعية الهيمنة هذه، وأن هذا النظام الأبوي تم الترخيص له له لهن

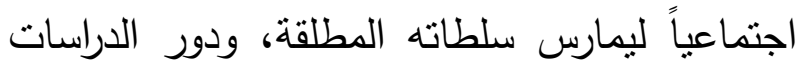
النسوية هي الكثف عن هذا ونزع السلطات المعرفية التي تمارس على المرأة أو توقيف عملها في انتاج المفاهيم المتعلقة بالمرأة . والنظام الأبوي على منطلقات النسوية نظام هيمنة بالهراه فهو منطق بنطوي في داخلة على منظومة من القيم

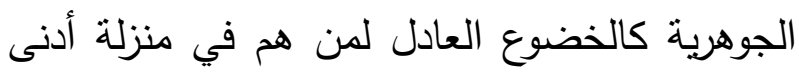
إلى من هم في مقام أعلى، كالعقلانية التي تميز

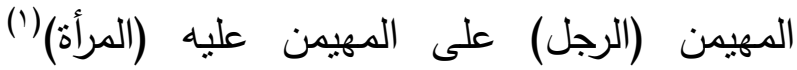
وتؤكد سيمون دي فوار ذللك بقولها: "إن المجتمع الذي شيده الرجل خدمة لمصلحته حدد وضع المرأة الذي صار فيما بعد مصدر عذاب للطرفين، وذلك من منظور أن المرأة كاهل نقيل على الرجل تابع له بكل كيانها ووجودها، فقد منعها هو من أن نستتد إلى نفسها، في الوقت الذي سيكون تحررها خدمة له ولها لو صار لها شيء تفعله في هذا العالم"(؟). وتجد المقولة البطريركية استمدادها من فوكو في لهاي توظيف نظريته في المعرفة والسلطة في افتراض بأن

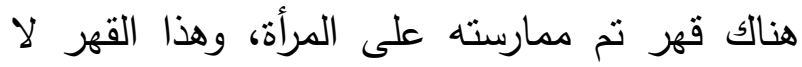

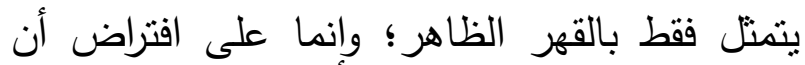

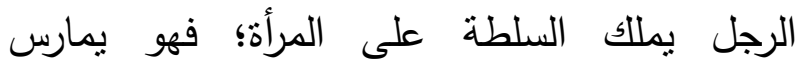
(1) السرد النسوي، عبد الهه ابر اهيم صعَ نقلا من كتاب الفلسفة

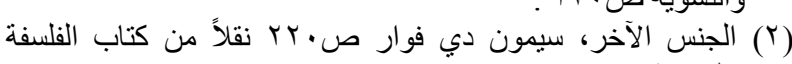

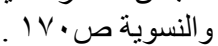


هذه الأطروحات من تحصيل حقوق اجتماعية للمرأة ؛ بقدر ما تتاضل من أجل نتكيل هوية للمرأة خارج

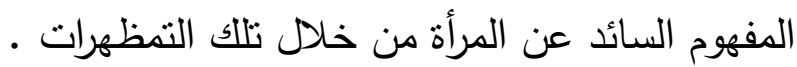
بل حتى كثثر من القضايا الفلسفية التي تتداول في خطابات النسوية الإسلامية مستتسخاً إلى حد كبير

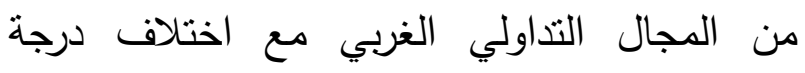

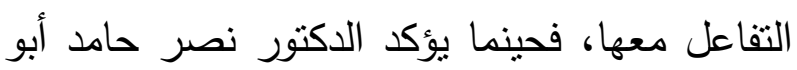

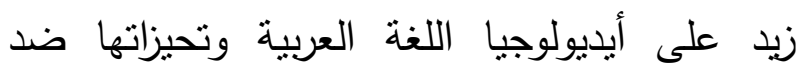
الأنثى، وأن اللغة العربية تمارس نوعاً من الطائفية

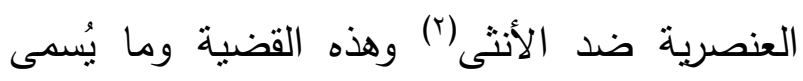
بذكورية اللغة، قد نم طرحها بالذات في عدد من الني

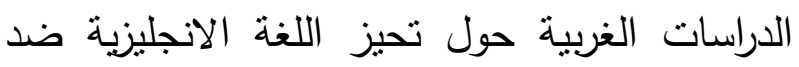

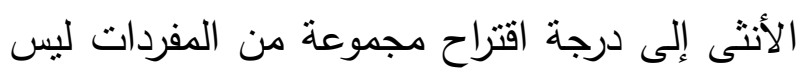

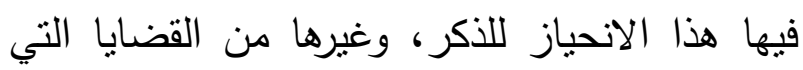

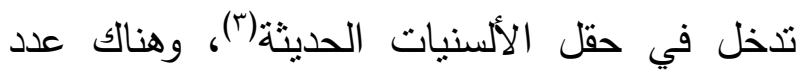
غير قليل من القضايا المشابهة ليس الغرض تعدادها

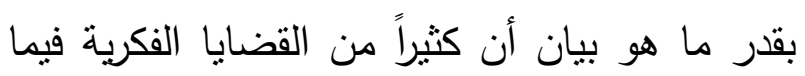
يتعلق بالنسوية الإسلامية مستورد من الفكر الغربي لئي مع بعض التحسينات التي تفرضها طبيعة النقل.

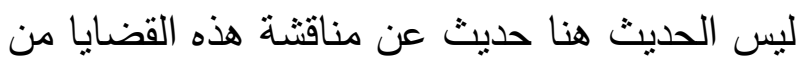

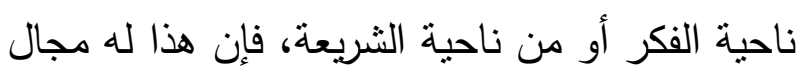

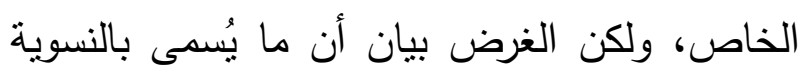
الإسلامية لا يبعد كثيراً عن الأسس الفلسفية الغربية

(Y) انظر تفصيل هذه الدعوى في كتابه: دوائر الخوف قراءة في خطاب

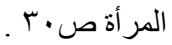
(r) انظر على سبيل المثال في هذه القضية: النسوية وما بعد النسوية
سلطة الرجل، ولذلك فالسياق الفرداني في الفلسفة

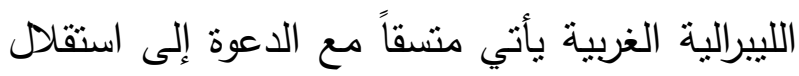

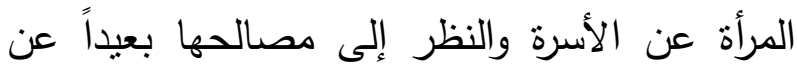

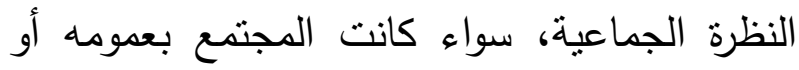
المجتمع الصغير الذي هو الأسرة . لنماعيهاء

المبحث الخامس: انعكاس الأسس القلسفية للنسوية الغربية على النسوية الإسلامية لا يهم الحديث عن اشتقاقات هذا المصطلح ولا أول من سكّه ولا مشروعية استخدامه بقدر ما يهر ماذا يعنيه من دلالات في الخطاب العربي المعاصر ، وما يبحثّ من القضايا التي صارت جزئاً من دن مهماته

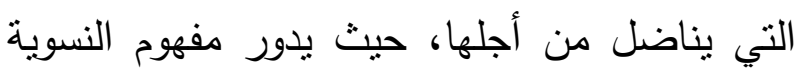

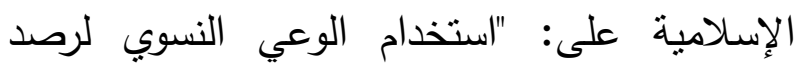

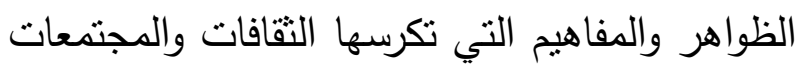
كجزء من الدين، ونقد ذلك من خلال قراءات جديدة

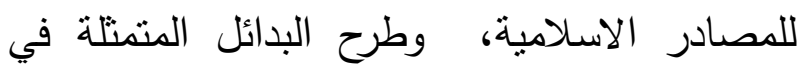
تقديم المساواة الانسانية بين الرجال والنساء"((1). ومع التحفظ على هذا المفهوم؛ فإنه عند استقراء مفردات ما يسمى بالنسوية الإسلامية، تظهر أغلب

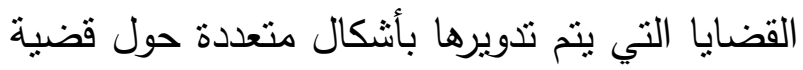

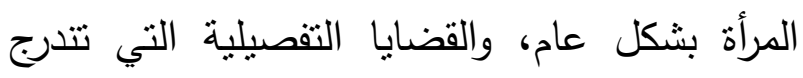

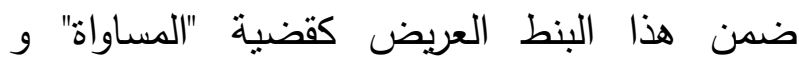
"الزينة" و "الحجاب" و "الإرث" و "التعدد" وغيرها من لهن القضايا التي تدور في هذا الفلك، فإنه مع ما تهنم بـ وعيه

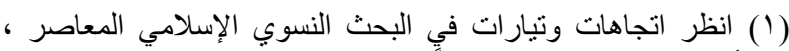

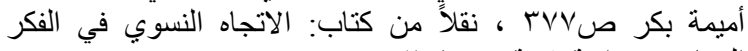


تعبر عن أفكارها بصفتها ناطق باسم الهوية الإسلامية؛ بخلاف الفكر الغربي الذي يحكي الواقع

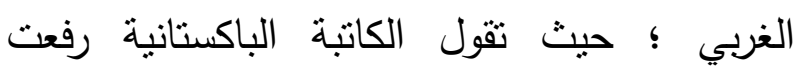

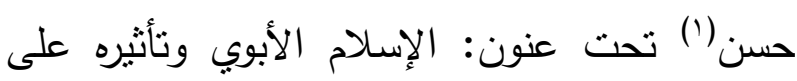
النساء المسلمات: "يتعين الآن توضيح أن الذين الذين

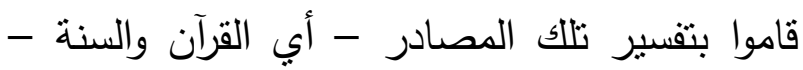
على مدى التاريخ الإسلامي الممتد كانوا من الرجال الذين انتحلوا لأنفسهم مهمة تحديد مكانة النساء

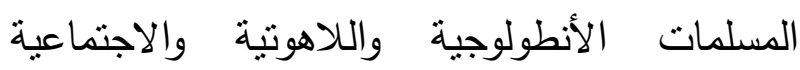

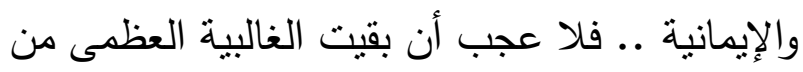

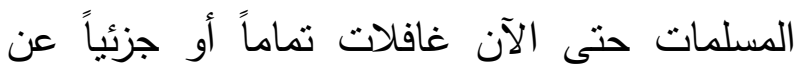
قدر الانتهاك الذي ألحقته مجتمعاتهن المتمركزة حول الرجال والتي يسودها الرجال"(؟) . ل

من هذا المنطلق فإن ما يُسمى بالنسوية الإسلامية لا تكمن مشكلتها مع الدين -كما تقول- حيث إنها تقرر أن الدين ليس مصدر اضطهاد للمرأة، بدليل

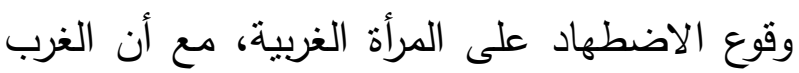

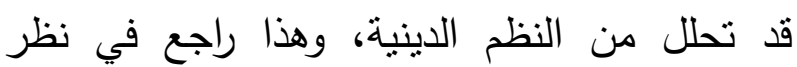
النسوية الإسلامية إلى القراءة الذكورية للإسلام وللانصوص الدينية التي شجعت على العنف والتمييز ضد المرأة، ولذلك فإنه وتحت ضغط المقولات لندات

(1) رفعت حسن باكستانيَّة الأصل، حصلت على شهادة الدكتور راه من

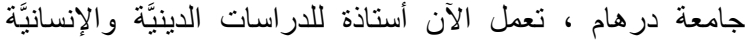

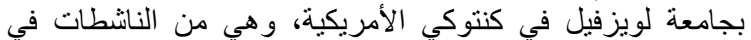

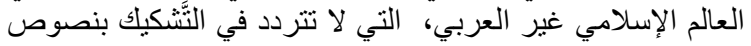

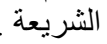

ولا عن مقولاتها التأسيسية، كاعتماد منهجية "التفكيك" ونظرية "المعرفة والسلطة" ومقولة "الجندر"

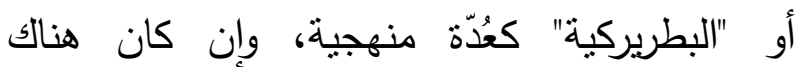
اختلاف في درجة الإعمال والاشتغال، حيث تكتفي الخطابات النسوية الغربية بتصفية جميع ما اتفقت عليه مما تُصنّفه داخل الدائرة الاجتماعية والثقافية التي شكّت أنوثة المرأة وتتزيل المعايير الجندرية

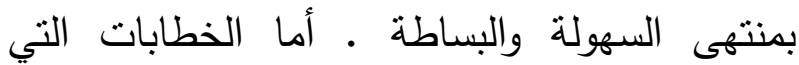
تُصنّف بأنها نسوية إسلامية فإنها وإن كانت نتنهي لنفس النتيجة بمعاييرها الجندرية ؛ إلا أنها تحتاج إلى خطوة أكثز صعوبة وأصعب مغامرة في محاولتها لتأويل النصوص الدينية التي تخالف هذه

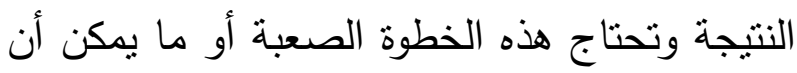
يُصطلح عليه بمهمة تأويلية إلى مزيد من البحث والدراسة والتتقيب بغية تضعيف أبي دلالات شرعية منية دينية تخالف النتيجة المبنية على المعايير الجندرية سواء بتكذيب النصوص النبوية أو قراءتها قراءة مخالفة لما اتفقت عليه المراجع الفقهية والأصولية بنتائجها المعروفة ـ المان إن الملاحظ في الدراسات النسوية الإسلامية مع ما تتتهجه من الفلسفة الغربية وجعل الأسس الفلسفية للنسوية ومقولاتها خلفية معرفية لها؛ أنها تقوم بعملية

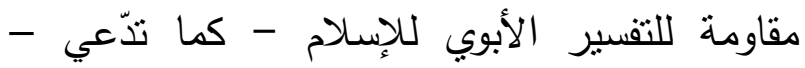
وإنهاءً لاحتكار الفهم الذكوري للمعرفة الدينية، وهذا

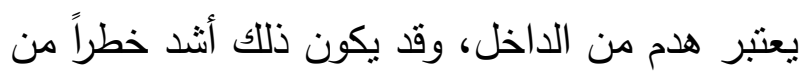
الفكر المستورد لأن ما يُسمى بالنسوية الإسلامية 
لقوة بنيتها المعرفية بقدر ما هو قلة الدراسات النقدية لها إن الملاحظ فيما يُسمى بالنسوية الإسلامية أنها أصبحت عبارة عن صدى لما توارثته الذاكرة الجمعية في الغرب من دلالات سلبية تجاه المرأة، ولذلك فقد استعارت مشكلة المرأة الغربية وما تعانيه من لناهيه

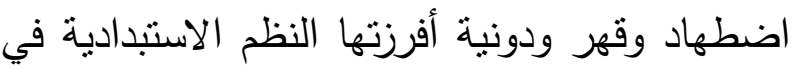
الغرب، إلى جانب النظرة الدونية كما تحكيه الفلسفة الغربية بشكل عام عن المرأة كما هي في الفلسفة اليونانية والوسيطة والحديثة، حيث قررت تلك الفلسفة نقضان المرأة، حيث تشير الفلسفة اليونانية إلى الى

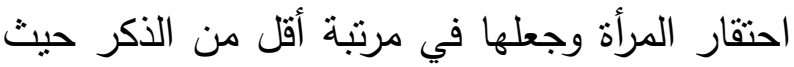

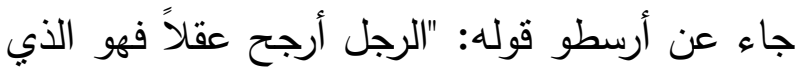

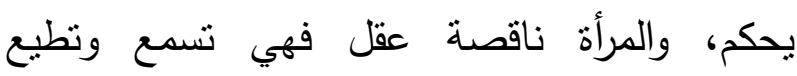
فحسب، والرجل بصفته الأعلى؛ فالأدنى -أي المرأة

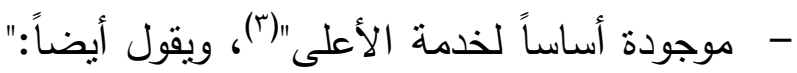

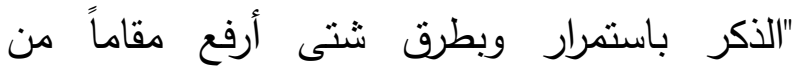
الأنثى"(؛)، وليس هذا فقط؛ فقد يوجد في الفلسفة الحديثة من هو ضد المرأة وضد فكرة مساواة المرأة

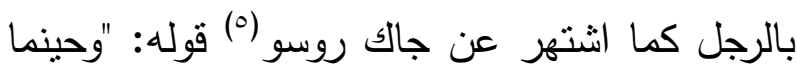

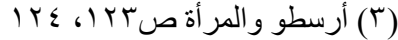

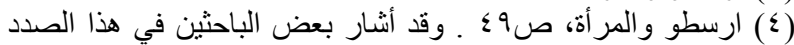

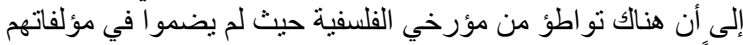

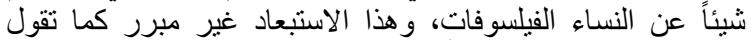

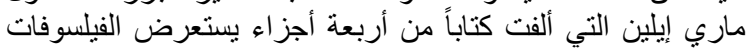

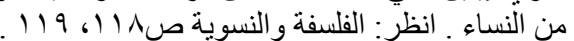

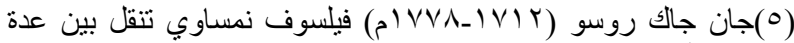

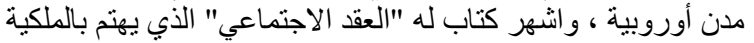

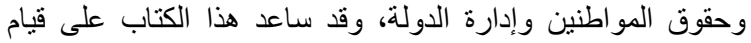

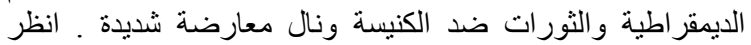

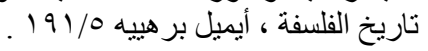

النسوية الغربية كمقولة "البطريركية" ومقولة "الجندر"

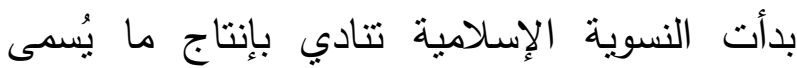
بـ"الفقه النسوي" داخل تراث الدين الإسلامي، وترى أنه في غاية الأهمية(')، حيث ترى أنه كما تقول

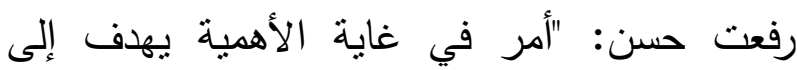
تحرير المسلمات بل والمسلمين من البُنى والقوانين الظالمة التي تجعل من علاقة الندية بين الرجال

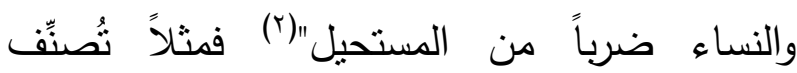
النسوية الإسلامية "الحجاب" على أنه نوع من قمع

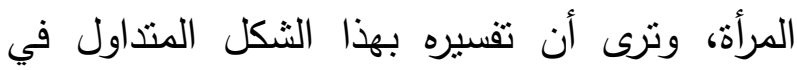
التراث الفقهي هو نوع من التفسير ذكوري الذي يروم

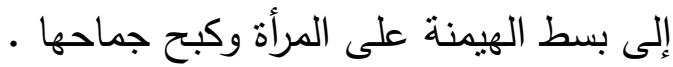
إلا هذه الخطابات على كثرتها تقتر إلى الاطلاع

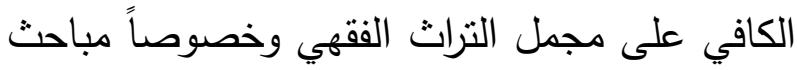
أصول الفقه وقراءة تاريخ النتريع قراءة معدّقة. لذلك فإن هذه الخطابات أصبحت مرمى سهام النقاد من

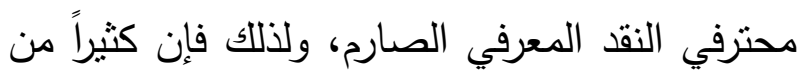
هذه الدراسات لم تصمد تحت مطرقة النقد، إلا أنها

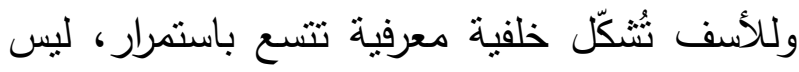

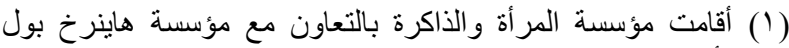

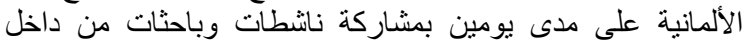

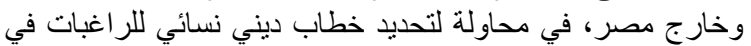

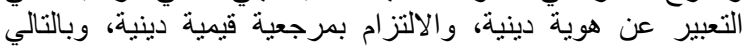

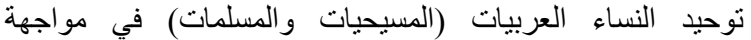

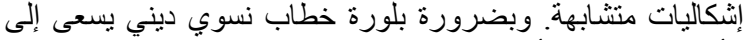

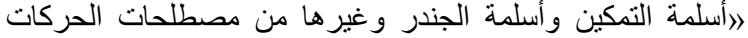

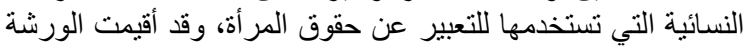

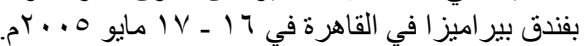

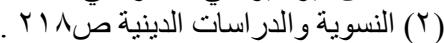


الإسلامية، وليس في الإسلام صراع بين المرأة والرجل وهكذا، وليس الغرض هنا مناقثة التفاصيل بقدر ما هو بيان لكيفية انعكاس اضطهاد المرأة في

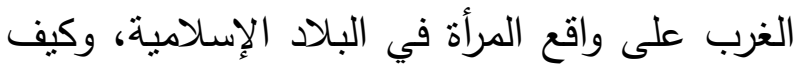
استفادت النسوية الإسلامية من الفلسفة الغربية في معالجة المشكلة المفترضة التي لم تكن مشكلة

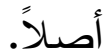

المبحث السادس: الموقف النقدي من الأسس

\section{القلسفية للنسوية}

ليس الغرض هنا نقد الفلسفات التي شكّت خلفية معرفية للاتجاهات النسوية بقدر ما هو نقد لتوظيف النسويات لهذه الفلسفات في تشكيل فلسفة نسوية قائمة بذاتها قادرة على منح المفاهيم والدلالات لكل ما له علاقة بالمرأة، من حيث مدى نجاحها أو لهاتئ إخفاقها في هذا التوظيف الفلسفي، ولذلك نجد من المفارقات الغربية التي لفتت نظر كثير من نقاد النسوية، أن النسوية نفسها استعانت في تأسيس فلسفتها بإعمال ذكورية سواء كانوا من رواد التفكيك

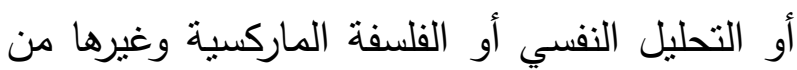
أجل نقد التصورات القائمة على مركزية الرجل، وهي اوني وعني

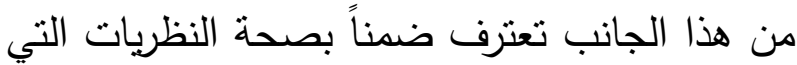
تتم صناعتها في البيئة الذكورية وحياديتها بغض
تشتكي المرأة من غبن عدم المساواة في الوضع الذي وضعها فيه الرجل، فهي مخطئة، فعدم المساواة هذا

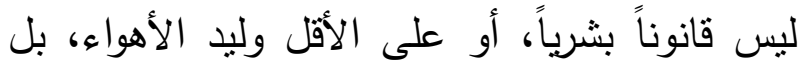

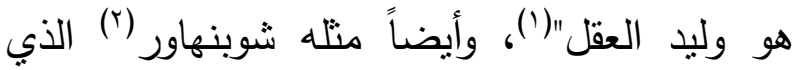
يقرر: "بألا يسمح للنساء بتاناً بتدبير شؤونهن

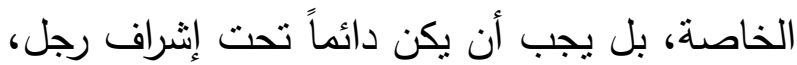
وأن المرأة بطبيعتها ناشز ومخطئة"(()) ومتل هذه المواقف الحادّة ضد المرأة كثيرة في الفلسفة الغربية،

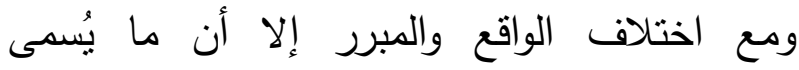
بالنسوية الإسلامية استعارت نفس الآليات الفلسفية والمقولات النسوية لعلاج هذه المشكلة التي لم تكن مشكلة أصلاً في البيئة الإسلامية المنطلقة من فن

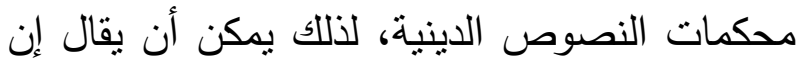

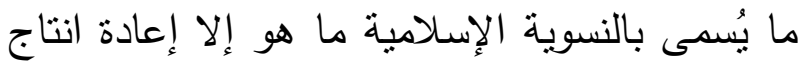

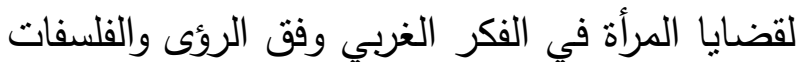
الغربية والتي تتصادم بشكل شبه تام مع واقع المرأة في البيئة الإسلامية ومع الرؤية الإسلامية ذاتها، فمثناُ الاضطهاد المفروض على المرأة في الغرب الإنه ليس هو الاضطهاد الممارس على المرأة في البيئة

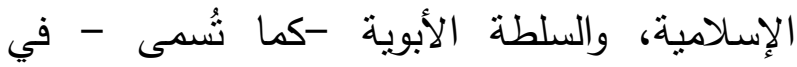
الغرب ليست هي مصدر السلطات في البيئات

(1) إيميل أو تربية الطفل من المها إلى الرشد، جان جاك روسوا

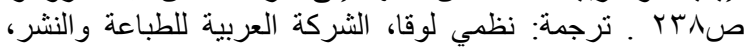
القاهرة

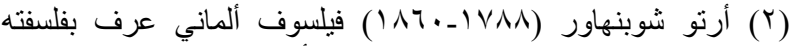

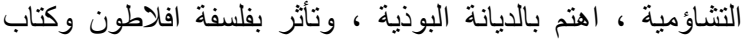

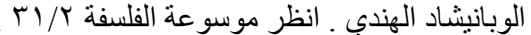

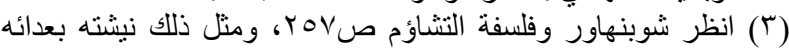

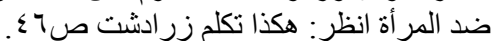


بل إن النسوية نفسها قد تمارس نوعاً من التسلط

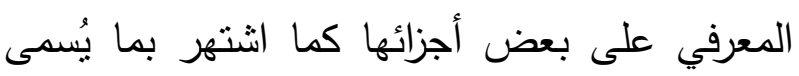

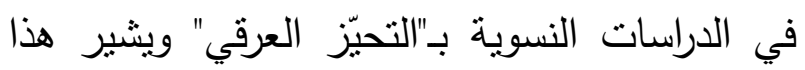
المصطلح إلى: "أسلوب للتفكير يستمد النظريات العامة الثاملة للمعرفة من منظور واحد ومحدود، ويشير عند النسويات الملونات إلى عملية بناء مجموع النظريات النسوية من وجهة النظر الغربية

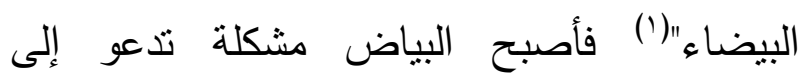

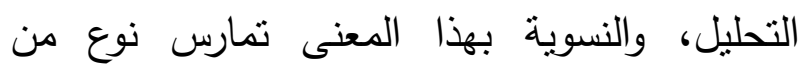

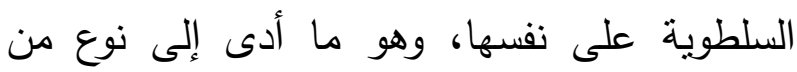
الصراعات الداخلية الذي يدل على عجز الحركات النسوية عن الاتحاد فيما بينها بالرغم من شعارات بلهات عجري الوحدة وهو ما اصلح عليه ب"تهافت الفتيات" . وهذا التباعد كان من أسباب الثنك في الكثير من لن الثنات المفاهيم التي تبنها الاتجاهات النسوية، زيادة على لمابل جرعة التطرف في كثير من نتائج هذ الحركات النسوية، بل تضخم الراديكالية فيها بحيث إنها انتهت في بعض محاولاتها إلى نهايات تتصادم مع الفطرة الأنثوية التي تريد أن تصنعها الاتجاهات النسوية، وخصوصاً فيما يتعلق بنزع الجانب الفطري في المرأة كفطرة الأمومة والإنجاب وتكوين أسرة ذات قطبين بئن (زوج/زوجة) ولذلك هذه الأطروحات المتطرفة والتي شجتها الاتجاهات الماركسية كما سبق لم تسنطع المواصلة في الطريق حتى النهاية، حتى في البلاد

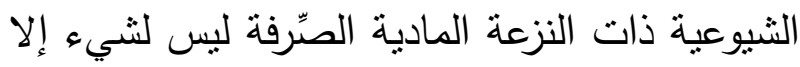

النظر عن وجاهة استخدامها في السياق النقدي، وصحة النظريات الفلسفية الذكورية معناه المشروعية المحايدة للاكر في إنتاج الفلسفة والمفاهيم الفلسفية وليس بالضرورة أن تؤدي إلى ممارسة قهر أو سلطة على المرأة كما هي نتائج المقولات البطريركية، وهذا لئل معناه إمكانية التجرد في إنتاج المفاهيم والدلالات الأنثوية، وهو ما تفعله النسوية بالضبط، فإن كثئ النيراً

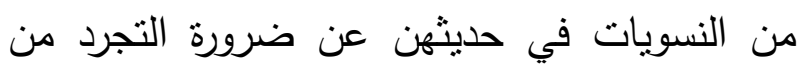

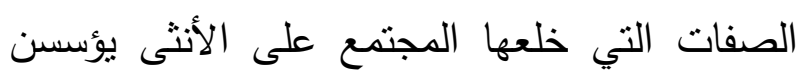
مفاهيماً ودلالات أنثوية منتاسيات في نفس الوقت الولت الونات أنهن في واقع الأمر نساء، وهذا مدعاة للتحيز الأنثوي اللاشعوري ضد الذكر وهن لا يكتبن بصفتهم

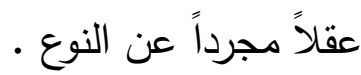
ومما نعاني منه الفلسفة النسوية استخدامها لمصطلح

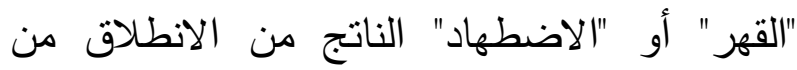
المقولات البطريركية، وهذا أدى بها إلى التعاطي مع التعان هذه المصطلحات تعاطياً مثالياً وليس واقعاً، بدليل

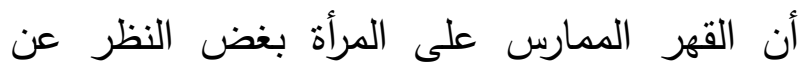
درجته هو جزء من القهر الممارس على الفقراء والمعوزين، والاضطهاد الحاصل على المرأة هو جزء هُء من هذا، بل إن استدعاء العنف في قضايا المرأة

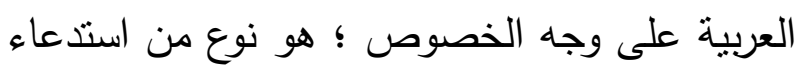

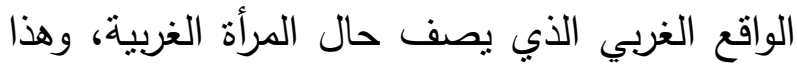
النقل لا يستتد إلى مبررات علمية واقعية، ولذلك فان لـان تصور النسوية الحلول السحرية للمرأة بمجرد استبعاد الرجل عن فلك المرأة هو نوع من اليوتيبيا الحالمة، 
أدنى إلى وجود تصور يميل إلى العنف الأيديولوجي وتشكّل صورة للأنثى بشعة تميل إلى المبالغة في الأنثوية الانفصالية في مجتمع يتكامل فيه الرجل لئل والمرأة .

\section{خاتمة}

بعد هذه الجولة السريعة في هذا الموضوع ألخّص أهم النتائج التي انتهي إلبها البحث:

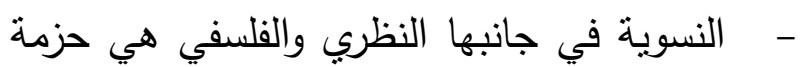
من النظريات المتداخلة، وهي تمنل في نفس الوقت دعامة منطقية للحركات التحررية، بل إنها تعتبر هي لهي لهي لهني الوقود الفعلي الذي أعطى المنظمات والجمعيات النسائية الشروعية في الانطلاق.

- - تعتبر الحركات الحقوقية المطالبة بالمساواة بين الرجل والمرأة بداية ظهور النسوية، وتطورت بعد ذلك إلى تكوين مفاهيم جديدة عن المرأة، وإعادة النظر في المفاهيم المتوارثة عنها، وقد تجاوزت النسوية الحركيّة إلى كونها فلسفة، لذلك أصبحت النسية ونئة فلسفة نقدية لا توضع في السياق النقدي •

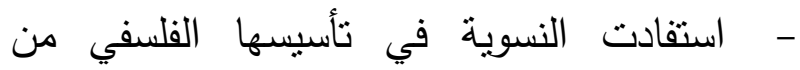
الماركسية وذللك في محاولها تفسير اضطهاد الرجل للمرأة، وأن هذا جزء من الصراعات الطبقية، وأن فئ فئن دونية المرأة هي نتيجة التطور التاريخي للمجتمعات هلن ولا تتعلق بالفروق البيولوجية بين الرجل والمرأة، وأن دور النسوية كفلسفة هو رد الوضع الإنساني كما هو قبل نشوء الصراع الطبقي بين الرجل والمرأة. - - تأسست الفلسفة النسوية في نظريتها المعرفيّة
لاستحالة اختراق الفطرة الأنثوية، حيث برهنت بشكل قاطع أن أي محاولة لنزع الجوانب الفطرية في المرأة

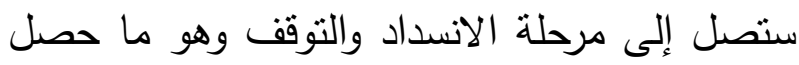

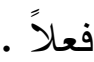
إن الملاحظ في الخطاب النسوي المستمد أسسه

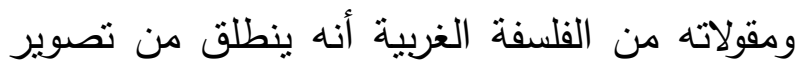

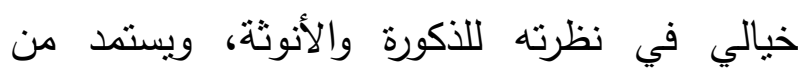
الإطار التخيلي الذي تمنحه اللغة في تصوير واقع

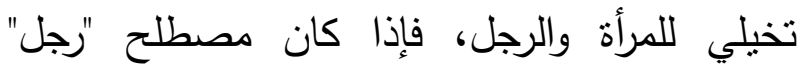
ومصطلح "امرأة" يحمل حمولة دلالية جنوسية؛ فإنه في نفس الوقت محمّل بالقيم الأخلاقية، وهذا ما لم يكن مجال بحث الاتجاهات النسوية، لذلك فإن الخطاب النسوي ذو المرجعية الغربية والمنزاح إلى الرؤية الماركسية المادية يعمل على تفريغ مصطلح

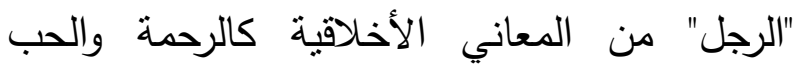
والعاطفة، وفي المقابل يتعاطى من حيث لا يشعر

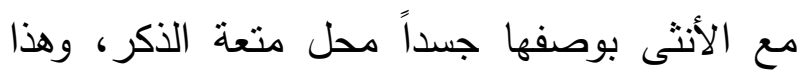
انعكس على ما يُسمى بالنسوية الإسلامية، لذلك فإن النها النسوية الإسلامية لا تتظر في صورة المرأة في الحضارة الإسلامية إلا صورة الجواري والقيان والمحظيات، دون النظر إلى المرأة بصفتها أمّ أو إلى إنهان عالمة أو ذات مكانة اجتماعية محفوظة الحقوق كما يشهد بذلك الواقع الحضاري الثابت في التاريخ، وهذا انعكس سلباً على القيمة الأخلاقية للذكورة من أنها تركيبة نقافية تنزع إلى التسلط والقهر بعيداً عن التهن المعاني الأخلاقية الإيجابية للرجل بوصفه ذكراً، وهذا 
- - كثير من القضايا الفلسفية التي تتداول في خطابات النسوية الإسلامية مستتسخاً إلى حد كبير من المجال التداولي الغربي مع اختلاف درجة التفاعل معها، هذا إضافة إلى جعل الأسس الفلسفية للنسوية ومقولاتها خلفية معرفية لها ـ - - إن الخطاب النسوي المستمد أسسه ومقولاته من الفلسفة الغربية ينطلق من تصوير خيالي في نظرته للأكورة والأنوثة، فإذا كان الرجل مرمى سهام النقد النسوي، فإن النسوية تتجاهل في نفس الوقت الجانب الأخلاقي للرجل، وهذا ما لم يكن مجال بحث الاتجاهات النسوية، ويتعاطى من حيث لا يشعر مع الأنثى بوصفها جسداً محل متعة الذكر فحسب .

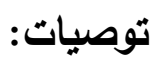
انطلقاً من أهمية دراسة الأسس الفكربة للنسوية فإني أوصي بدراسة بعض المواضيع المكملة لهذا الموضوع وهي كالتالي:

- - المنطلقات الفكرية للنسوية؛ ولاية الرجل على المرأة أنموذجاً - المنطلقات الفكربة للنسوبة ، مدونات التشربع المتعلقة بالمرأة أنموذجاً

\section{فهرس المراجع}

- - الاتجاه النسوي في الفكر المعاصر دراسة نقدية

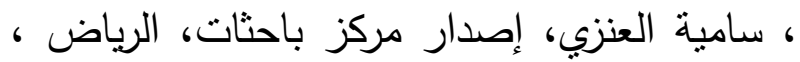

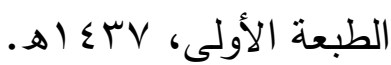

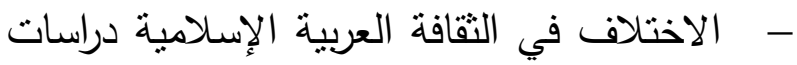
جندرية، آمل قرامي، دار المدار الإسلامي، بيروت، الإهيه
على فلسفة فوكو في السلطة والمعرفة، حيث ترى الفلسفة النسوية أن المعرفة تشكلت بتأثز من النظام الأبوي السلطوي ولابد من إيجاد نظرية معرفية نسوية بحيث تتطلق من وجهة نظر نسوية دون سلطة تمارس عليها من قبل الرجل. - قدمت الفلسفة التفكيكية دعماً نقدياً للاتجاهات النسوية وذلك في إبراز الهوبة النسوية الغائبة مقارنة بالهوية الذكورية الحاضرة، تعيد من خلالها الاعتبار لطرف الثنائية (الذكر/الأنثى) المهوش، وتقسّم المعاني الدلالية بشكل متساوي، وتقضي على أي انحياز أو تمركز ذكوري يؤدي إلى تغييب الآخر أو إقصائه . - - تكنسب مقولة "الجندر" أهميتها كرافد أساسي للأسس الفلسفية للنسوية، من حيث تسعى هذه المقولة إلى تصفية جميع السياقات الاجتماعية والثقافية التي تميز الرجل عن المرأة، بحيث تجعل الجميع كنوع واحد ، وأي إضافة على هذا النوع إنما هو من صنيع الثقافة والمجتمع • - تعتبر البطريركية/الأبوية أداةً جوهرية في في الدراسات النسوية الغربية، ويمكن أن تكون من أهم الأدوات الممتدة من الأسس الفلسفية للنسوية، حيث ترى أن الرجل هو الدسؤول عن قمع العرأة واضطهادها وخصوصاً داخل نظام الأسرة، ويتخذ ذلك صوراً متعددة بدءً من تقسيم العمل على أساس الجنس والتتظيم الاجتماعي لعملية الإنجاب، إلى المعايير الداخلية للأنوثنة وغيرها. 
فياض، دار حوران للطباعة والنشر، دمشق الطبعة

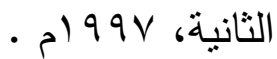
- - دليل أكسفورد للفلسفة، تحرير : تد هوندرتش، ترجمة: نجيب الحصادي، المكتب الوطني للبحث

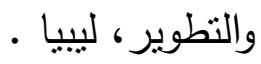

- - دليل الناقد الأدبي ميجان الرويلي وسعد البازعي، المركز الثقافي العربي، بيروت، الطبعة

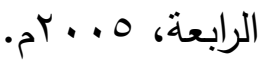
- - دوائر الخوف قراءة في خطاب المرأة، نصر

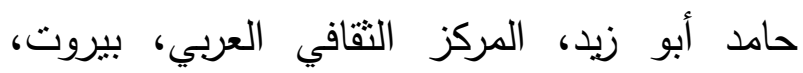

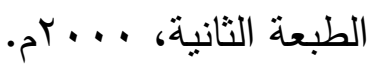

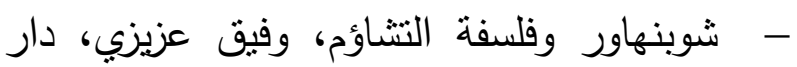

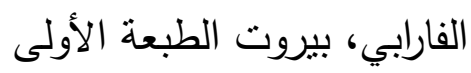

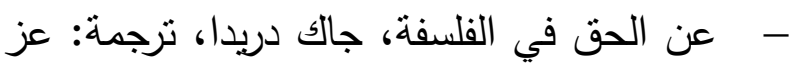
الدين الخطابي، المنظمة العربية للترجمة، بيروت،

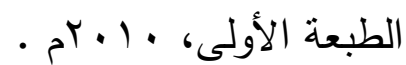

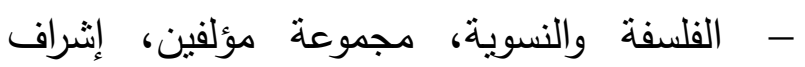

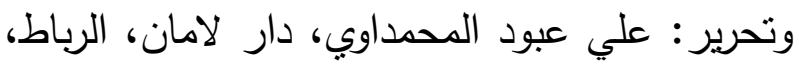

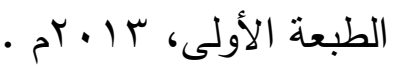
- - قضايا المرأة في الخطاب النهاب النسوي المعاصر الحجاب أنموذجاً، مالكى الجهني، هركز نماء

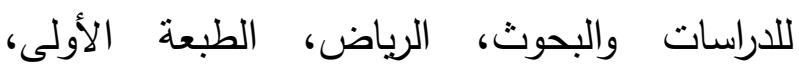
. 10

- مبادئ الثيوعية، فردربك إنجلز، المكتبة الثيوعية الماوبة. - - مدخل في نظرية النقد النسوي وما بعد النسوية،

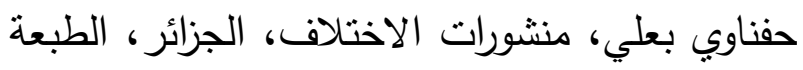

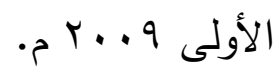
- - المرأة المخصية ، جيرمين غرير ، ترجمة: عبد الله بديع فاضل، الرحبة للنشر والتوزبع ، دمشت، عرئ، ترجهن

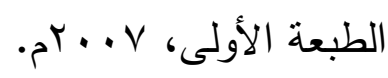

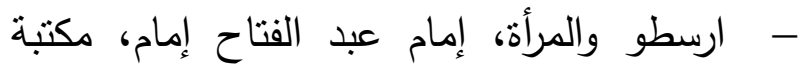
مدبولي، القاهرة، الطبعة الأولى، 997 ام ـ - - استعباد النساء، جون ستيوات مل، ترجمة إمام

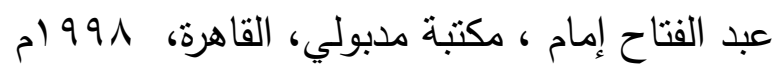

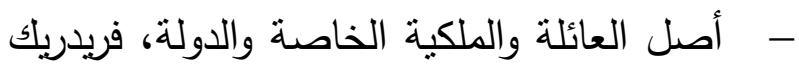
إنجلز، ترجمة: أحمد عز العرب، دار الطباعة الحديثة/

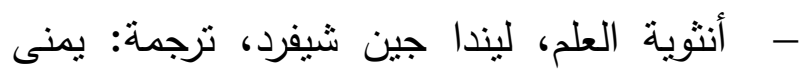
طربف الخولي، كتاب عالم المعرفة، المجلس الوطني

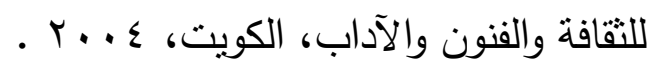

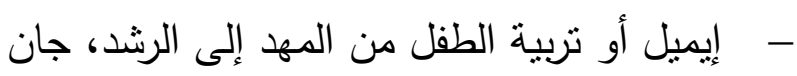
جاك روسوا • ترجمة:نظمي لوقا، الثركة العربية للطباعة والنشر ، القاهرة . - - بنيان الفحولة أبحاث في المذكر والمؤنث،

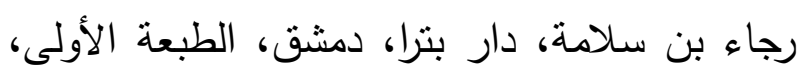
. 0 - - تـاريخ الفلسـفة، إميـل برهييـه، ترجمــة: جـورج

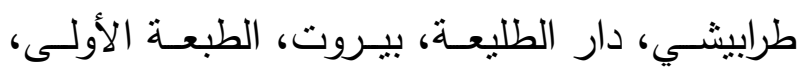
. $9 \wedge \mathrm{r}$ - - التفكيكية إرادة الاختلاف وسلطة العقل، عادل

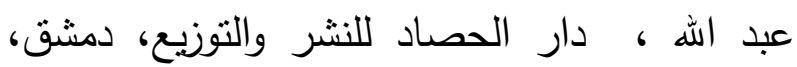

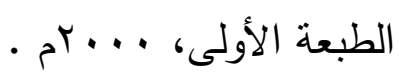
- - الثورة المغدورة نقد التجربة الستالينية، ليون

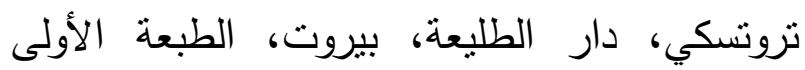
- م) 971 - الجنس الآخر، سيمون دو بفوار، ترجمة: رحاب

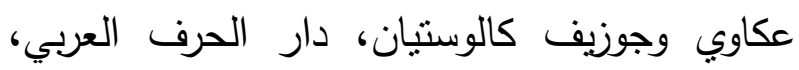
بيروت، الطبعة الأولى، 10 • بام.

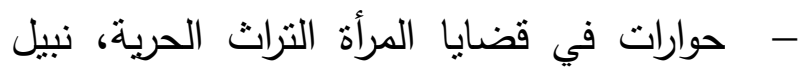




$$
\text { بيروت، الطبعة الأولى، ؟99 ام • }
$$

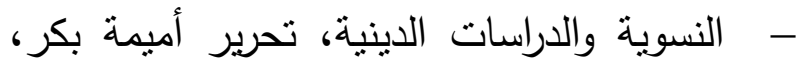
ترجمة: رندة أبو بكر، مؤسسة المرأة والذاكرة، (r

- - النسوية وما بعد النسوية، سارة جامبل، ترجمة،

أحمد الثامي، المجلس الأعلى للتقافة، القاهرة .

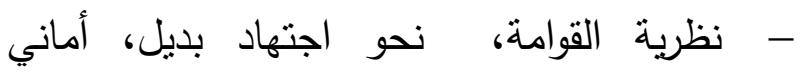
صالح، ورشة عمل "القوامة نحو رؤية اجتهادية بديلة" المركز القومي لسكان البرنامج القومي لتمكين الأسرة ومناهضة ختان الإناث، القاهرة، القاهرة:

$$
\text { • } 1 T / r / 17
$$

- - هكذا تكلم زرادشت، نيتشه، ترجمة: فيلكس

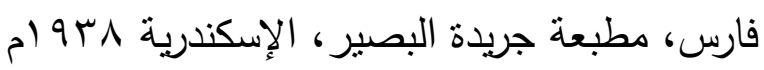

$$
\begin{aligned}
& \text { الطبعة الأولى، ـ ا ـ بام. } \\
& \text { - - المركزية الغربية، عبد الله ابراهيم، الدار العربية }
\end{aligned}
$$

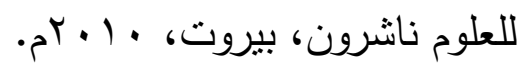

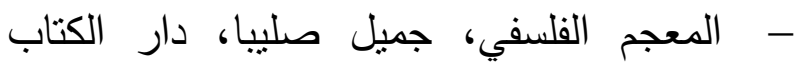

$$
\begin{aligned}
& \text { اللبناني، - 191 } \\
& \text { - مفاهيم اصطلاحية جديدة معجم مصطلحات } \\
& \text { التقافة والمجتمع، طوني بينيت وآخرون، ترجمة: }
\end{aligned}
$$

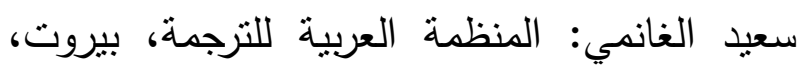

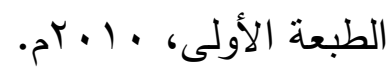

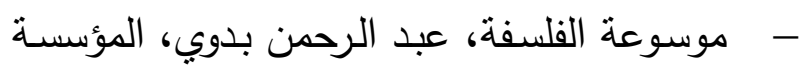

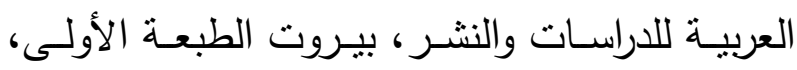

$$
\begin{aligned}
& \text { - ) } 9 \wedge \varepsilon \\
& \text { - ميشيل فوكو المعرفة والسلطة، عبد العزيز }
\end{aligned}
$$

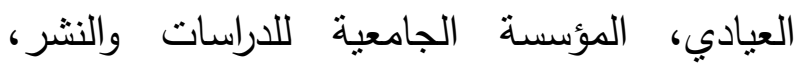

\title{
The Philosophical Foundations of Feminism (Presentation \& Criticism) And the Impact of that on Islamic Feminism
}

\author{
Dr. Khalid bin Abdul-Aziz al-Saif \\ Associate Professor College of Shari 'ah \& Islamic Studies \\ Department of Islamic Doctrine \& Contemporary Ideologies \\ Qassim University
}

\begin{abstract}
Feminist movements are one of the most controversial movements, and these movements would not have been around had it not been for philosophical support. In general, their philosophy is based on postmodern philosophies, which are considered general knowledge of the overall pan of what is raised in feminist criticism. The
\end{abstract}


importance of knowing these Western philosophical foundations of feminism comes to light when unveiling them from the joints of Arab feminist thought where it becomes clear to the critic that Arab feminist thought is only an echo of Western feminist thought. 